PALEO

Revue d'archéologie préhistorique

$30-2 \mid 2020$

Varia

\title{
La grotte ornée de la Mairie (Teyjat, Dordogne, France) dans les musées. Fragments d'un discours symbolique
}

The decorated cave of La Mairie (Teyjat, Dordogne, France) in museums.

Fragments of a symbolic discourse

Patrick Paillet, Elena Paillet et Camille Noûs

\section{OpenEdition \\ Journals}

Édition électronique

URL : http://journals.openedition.org/paleo/5602

DOI : $10.4000 /$ paleo.5602

ISSN : 2101-0420

Éditeur

SAMRA

Édition imprimée

Date de publication : 1 septembre 2020

Pagination : 222-249

ISSN : $1145-3370$

Référence électronique

Patrick Paillet, Elena Paillet et Camille Noûs, « La grotte ornée de la Mairie (Teyjat, Dordogne, France) dans les musées. Fragments d'un discours symbolique », PALEO [En ligne], 30-2 | 2020, mis en ligne le 30 septembre 2020, consulté le 26 novembre 2020. URL : http://journals.openedition.org/paleo/5602 ; DOI : https://doi.org/10.4000/paleo.5602

\section{(9) $\odot \Theta \Theta$}

PALEO est mis à disposition selon les termes de la licence Creative Commons Attribution - Pas d'Utilisation Commerciale - Pas de Modification 4.0 International. 


\section{LA GROTTE ORNÉE \\ DE LA MAIRIE \\ (TEYJAT, DORDOGNE, \\ FRANCE) \\ $\frac{2}{2}$

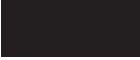

DANS LES MUSÉES.

FRAGMENTS D'UN

DISCOURS SYMBOLIQUE

Patrick Pailleta,

Elena Paillet ${ }^{b}$, Camille Noûsc

a. UMR Histoire naturelle de l'Homme préhistorique (HnHp); Muséum national d'histoire naturelle, Sorbonne Université, Université Perpignan Via Domitia (UPVD), CNRS, Musée de l'Homme, 17, place du Trocadéro et du

11 novembre, FR-75116 Paris - patrick.paillet@mnhn.fr

b. DRAC-SRA Bretagne, UMR, Centre de Recherche en Archéologie, Archéosciences, Histoire (CReAAH), Université de Rennes I, Avenue Charles Foulon, 35700 Rennes - elena.paillet@culture.gouv.fr

c. Associée au laboratoire Cogitamus
IL

La grotte de la Mairie à Teyjat (Dordogne) abrite un dispositif pariétal constitué d'une cinquantaine de représentations animales (rennes, cerfs, aurochs, bisons, chevaux, ours et animaux indéterminés) et de nombreux tracés indéterminés qui ont pour caractéristique commune et originale d'être tous gravés sur les vestiges d'un imposant et vieil édifice stalagmitique (planchers, cascade, coulée, etc.) démantelé. Sa découverte date du début du XXème siècle. La question du statut de cet art pariétal d'entrée de grotte, associé à deux importants niveaux d'occupations du Magdalénien supérieur, s'est posée dès les premières recherches conduites par P. Bourrinet, H. Breuil et D. Peyrony. La mobilité de certaines dalles de calcite, leur fragmentation et leur relation avec les occupations préhistoriques ont fait naître l'idée que la grotte de la Mairie était un site « mixte », pariétal et mobilier à la fois. Il y a bien quelques objets ornés sur os, bois de cervidés et sur matériaux lithiques (jais et calcite) découverts dans les deux niveaux de Magdalénien, mais le dispositif gravé sur les grandes plaques de concrétion relève bien dans sa totalité d'un art de paroi, immeuble par destination. Les archives, les publications et nos propres travaux dans le cadre d'un Projet Collectif de Recherche conduit de 2012 à 2017 en servent la démonstration. Mais cette enquête montre aussi que la fragmentation du dispositif pariétal de la Mairie a des causes multiples, anthropiques et surtout naturelles, et qu'il convient d'apprécier le degré d'intégrité du dispositif pariétal. Plusieurs dalles et blocs redécouverts dans les musées, mobiles par accident, ont ainsi retrouvé leur origine pariétale. Ils contribuent à compléter le dispositif iconographique et à réunifier son discours symbolique.
PALE0 30 | t. 2

JUILLET 2020

PAGES 222 À 249

MOTS-CLÉS Teyjat, Grotte de la Mairie, Art pariétal, Art mobilier, Magdalénien, Calcite. 
The decorated cave of La Mairie (Teyjat, Dordogne, France) in museums. Fragments of a symbolic discourse.

The cave of La Mairie in Teyjat (Dordogne) offers a parietal device constituted of about fifty animal representations (reindeer, deer, aurochs, bison, horses, bears and indeterminate animals) as well as many indeterminate traces whose shared and original feature is to be engraved on the remains of an old imposing stalagmitic building (floors, cascade, casting, etc.) dismantled. Its discovery dates from the beginning of the 20th century. The question of the status of this art in the entrance of the cave, associated with two important levels of occupations of the Upper Magdalenian, existed since the first researches conducted by P. Bourrinet, H. Breuil and D. Peyrony. The mobility of some calcite slabs, their fragmentation and their relation with prehistoric occupations have led to the idea that the Cave of La Mairie was a "mixed" site, with both rock art and portable art. There are indeed some decorated objects on bone, antler and lithic materials (jais and calcite) discovered in the two Magdalenian levels, but the engraved dispositive on the large elements of concretion are constitutive of parietal art, immovable by destination. Archives, publications and our own work in the frame of a Collective Research Project conducted from 2012 to 2017 serve this demonstration. But this survey also shows that the fragmentation of the parietal art of La Mairie has multiple causes, anthropic and especially natural, and that one must understand to appreciate the degree of integrity of the art. Several slabs and blocks were rediscovered in the museums, mobile by accident, thus founding their parietal origin. They contribute to complete the iconographic device and to reunite its symbolic discourse

\section{INTRODUCTION}

Si la grotte de la Mairie à Teyjat (Dordogne) est célèbre dans le monde de la Préhistoire pour son art pariétal finement gravé et pour le réalisme de ses figures animales, qui aurait représenté selon certains auteurs une sorte de parangon de l'art figuratif paléolithique (Leroi-Gourhan 1971), elle est aussi connue, dans des cercles cette fois-ci plus confidentiels, pour la fragmentation de son dispositif pariétal consécutive à celle des calcites lui ayant servi de supports. En effet, l'édifice stalagmitique s'est substitué sous la main des artistes magdaléniens à la piètre roche encaissante, une brèche calcaire, ce qui est particulièrement original dans le paysage des grottes ornées paléolithiques. Il a souffert diversement des affres du temps, de la nature, des Magdaléniens, des visiteurs modernes, des fouilleurs et probablement même des aménageurs, des architectes et autres ingénieurs qui lui voulaient pourtant du bien. Cette souffrance est, et fut telle, que la question de l'intégrité du dispositif pariétal, de sa reconstitution ou de sa restitution, de sa nature même (pariétale et/ou mobilière ?) est devenue centrale dans les débats scientifiques, ainsi que dans les mesures prises pour en assurer sa conservation. L'art pariétal de la Mairie est bien un art de fragments, un art quasi-mobile écrivent certains (Tosello 2003), au moins en son état actuel de conservation, un art peut-être même si incomplet que sa puissance symbolique pourrait en avoir souffert, à la mesure du délitement de son support de calcite ambrée. Si les publications sur la grotte sont bien peu nombreuses, il n'en est pas une qui ne fasse mention soit entre deux lignes, soit de manière beaucoup plus explicite, de la mise à mal, voire de la « ruine » (Capitan et al. 1905) des supports. Ainsi, peu à peu, au gré des visites successives faites dès le XIXème siècle, des fouilles d'É. Perrier du Carne d'abord et de P. Bourrinet ensuite, dont l'impact est notablement visible dans les galeries et dans le paysage, et des multiples travaux d'aménagements (murs, portes, cheminements, etc.), la grotte, et plus particulièrement les vieux planchers et les coulées stalagmitiques de l'entrée, se sont inexorablement dégradés. Face à l'urgence sanitaire, dont la prise de conscience a été progressive mais bien réelle, des réponses parfois empiriques ont été apportées. On a même suggéré la dépose pure et simple des œuvres pariétales, comme on dépose une mosaïque antique dans un musée. La grotte de la Mairie est devenue un formidable laboratoire expérimental où aux creusements succédaient les comblements, aux constructions les destructions, aux fers les inox, à la bougie, aux flammes de magnésium ou aux lampes à carbure l'électricité.

Afin de mesurer l'importance des dégradations subies par la cavité et leurs conséquences sur la lecture et l'interprétation de son art pariétal, un tour d'horizon historique s'impose tant du point de vue des activités scientifiques depuis sa découverte officielle que du point de vue des aménagements successifs réalisés dans la cavité. Mais entendons-nous bien, cet article est tout sauf un procès intenté aux anciens ou à nos contemporains, ni même aux différents services patrimoniaux qui ont eu à un moment ou un autre des responsabilités en matière de gestion de la grotte, d'autorisation ou d'exécution de travaux, d'autorisations de fouilles ou de relevés d'art rupestre (Gernigon 2011). Relater les faits ou les événements, piocher 
dans les archives inédites, lire entre les lignes des articles et des monographies par exemple, c'est aussi se donner les moyens de mieux comprendre l'histoire de la cavité, de mieux en restituer l'hypothétique état originel, ce qui semble bien être un vœu pieux, mais surtout de faire parler ces bouts de calcite qui ont été retrouvés dans les musées ou dans les vieux déblais encore présents dans la grotte.

\section{DES FRÉQUENTATIONS ET DES RECHERCHES AUX CONSÉQUENCES IMPRÉVUES}

La grotte de la Mairie s'ouvre au sud, à 150 m d'altitude, au cœur du village de Teyjat (Dordogne), en rive droite de la Marcorive (petit affluent du Bandiat) et au pied d'un escarpement constitué de brèches de cryptokarstification dans les calcaires dolomitiques de l'étage Bajocien (Jurassique moyen) (fig.1). Elle est formée de deux galeries divergentes. La galerie principale, réseau fossile, d'environ 90 m de long, abrite les œuvres pariétales dans sa partie vestibulaire. La deuxième galerie, plus modeste, d'environ $30 \mathrm{~m}$ de long, fortement déclive, constitue un regard sur des niveaux inférieurs actifs, drainés par une rivière souterraine anciennement captée dans le centre bourg et qui finit par se jeter dans la Marcorive (Dandurand 2013, 2014, 2017 et 2019). En 2017, plusieurs échantillons de sédiments détritiques et de spéléothèmes hors champ orné ont été prélevés pour datations OSL, U/Th, 14C et pour analyses granulométriques (Dandurand 2019) (fig.2). Encore très discrète dans le paysage au cours du XIXe siècle et seulement accessible par une entrée étroite en forme de soupirail de $50 \mathrm{~cm}$ sur $80 \mathrm{~cm}$, située à environ $10 \mathrm{~m}$ de hauteur sur la paroi rocheuse, encombrée par un éboulis, la grotte de la Mairie est fréquentée très tôt comme en témoignent plusieurs graffitis (Favraud 1905, p. XCIX-CIII), au sommet de la cascade stalagmitique et uniquement à cet endroit. On peut lire, outre des lettres isolées, des morceaux de phrases illisibles et des palimpsestes d'incisions incompréhensibles, plusieurs dates $(1803,1851,1856$, etc.) et quelques patronymes connus à Teyjat et plus largement dans la région, entre les années 1860 et 1880, comme Jules Mazorie, Donzeau, Jacques Coussy² et Alphonse Bonnithon ${ }^{3}$.

Vers 1880 (la date n'est pas précise), Édouard Perrier du Carne, notaire à Angoulême, probablement averti de l'existence de la grotte dont l'entrée est certainement un peu élargie suite aux récents travaux de construction de l'école et de la mairie, y effectue une fouille localisée d'un mètre carré dans les premiers mètres de la galerie principale alors difficile d'accès (Perrier du Carne 1889). Il fait également effectuer une longue et profonde tranchée dans les dix premiers mètres de la galerie. La fouille principale se situe à 12 mètres plus précisément de l'ouverture de la grotte, probablement au droit de la principale cascade stalagmitique ornée. Ce sondage

[1] On ne sait s'il s'agit du conseiller municipal, puis du maire de Teyjat de 1877 à 1896 , Pierre-Adrien Donzeau, ou de son fils Jean Donzeau).

[2] Jacques Coussy est inscrit au moins à deux reprises. Ce patronyme pourrait être associé à la date de 1803. C'est un nom de famille courant dans la région. On connait un Jacques Coussy né à Teyjat en 1745. Cela pourrait correspondre à une visite dans la grotte en 1803 (à l'âge de 58 ans).

[3] Le nom a été déduit du graffiti AB et du prénom Alphonse. Un Alphonse Bonnithon est né à Teyjat à une date inconnue et est mort à Paris en 1873. profond de $70 \mathrm{~cm}$ livre quelques silex, des vestiges d'industrie osseuse, un peu de faune et trois objets d'art mobilier magdaléniens. Un seul de ces objet (sacrum gravé d'un cheval) est parvenu jusqu'à nous (Saint-Périer 1948 p. 230-232) (fig.3). Alors qu'il a prospecté avec rigueur dans la cavité, Perrier du Carne ne mentionne pas la présence de blocs de calcite, et encore moins de gravures à cette époque où l'art pariétal paléolithique n'est pas encore connu (hormis Altamira et peut-être la grotte Chabot dans le Gard) et surtout reconnu.

Au XIXe siècle, la grotte est peu mentionnée mais en 1888 , Pierre Henri Ribault de Laugardière écrit au sujet de la commune de Teyjat : " ... terminons maintenant ce chapitre en signalant, parmi les curiosités du sol : $1^{\circ}$ Dans le terrain calcaire et près de l'église une grotte à cristallisation [...] » (Laugardière 1888 - p. 330).

La grotte est ensuite évoquée de manière (religieusement) anecdotique dans une notice manuscrite nommée "L'ancien et le nouveau Périgord», qui porte sur les paroisses du Périgord. Elle est rédigée par un érudit local, le Chanoine Hippolyte Brugière, à la fin du XIXème siècle: "Près de l'église grotte à cristallisation où passe le ruisseau qui forme la fontaine du bourg. On y remarque deux blocs de stalagmites dont l'un ressemble, dit-on, à la Vierge tenant dans ses bras l'Enfant Jésus et l'autre à St-Roch, deux patrons de la paroisse » (Brugière sd).

Dans le contexte des nouvelles découvertes de grottes ornées en Dordogne (La Mouthe, 1895 ; Font-de-Gaume et Combarelles, 1901 ; Bernifal, 1902), Émile Cartailhac suggère en août 1903 à Henri Breuil l'exploration de la grotte, après avoir lu la publication de É. Perrier du Carne. Cette prospection est confiée à Denis Peyrony. Selon les sources officielles, c'est ce dernier qui découvre les premières gravures pariétales fin août - début septembre 1903 sur l'imposante coulée de calcite qui émerge d'un dépôt de pente comblant l'entrée de la grotte (cône d'éboulis abrupt). La cascade, dont la surface est parfaitement régulière contrairement au calcaire encaissant, est haute de 1,70 mètre, profonde de 1,80 mètre et large d'environ 2 mètres. Il s'agit de la partie principale d'un édifice stalagmitique démantelé. Elle est presque entièrement recouverte d'un enduit d'argile et constituée de 3 plaques encore solidaires qui sont les panneaux que nous avons dénommés D (dalle aux bisons), E (dalle qui se situe aujourd'hui en position secondaire) et $F$ (cascade proprement dite avec la frise des aurochs), bien que déjà profondément fissurées (Chauvet 1905 - p. XLV-XLIXI).

À l'issue d'un premier examen et à la faveur d'un nettoyage, d'un lavage et d'un brossage " soigneux » (Capitan et al. 1903 - p. 366 ; Chauvet 1905 - p. XLVI), D. Peyrony identifie et calque $^{4} 9$ figures soit 2 aurochs, 2 bisons, 2 chevaux et 3 rennes sur les 24 figures actuellement recensées (6 aurochs, 5 chevaux, 2 bisons, 8 rennes, 1 ours et 2 animaux indéterminés). L'expertise et l'authentification

[4] Dans un courrier adressé à Breuil en avril 1904 il dit avoir découvert de nouveaux dessins sur la cascade et avoir adressé les calques à L. Capitan (lettre de Denis Peyrony à Henri Breuil, 5 avril 1904). Des relevés de la main de Peyrony, mais aussi de Capitan, existent donc, mais nous ne les avons pas retrouvés. 


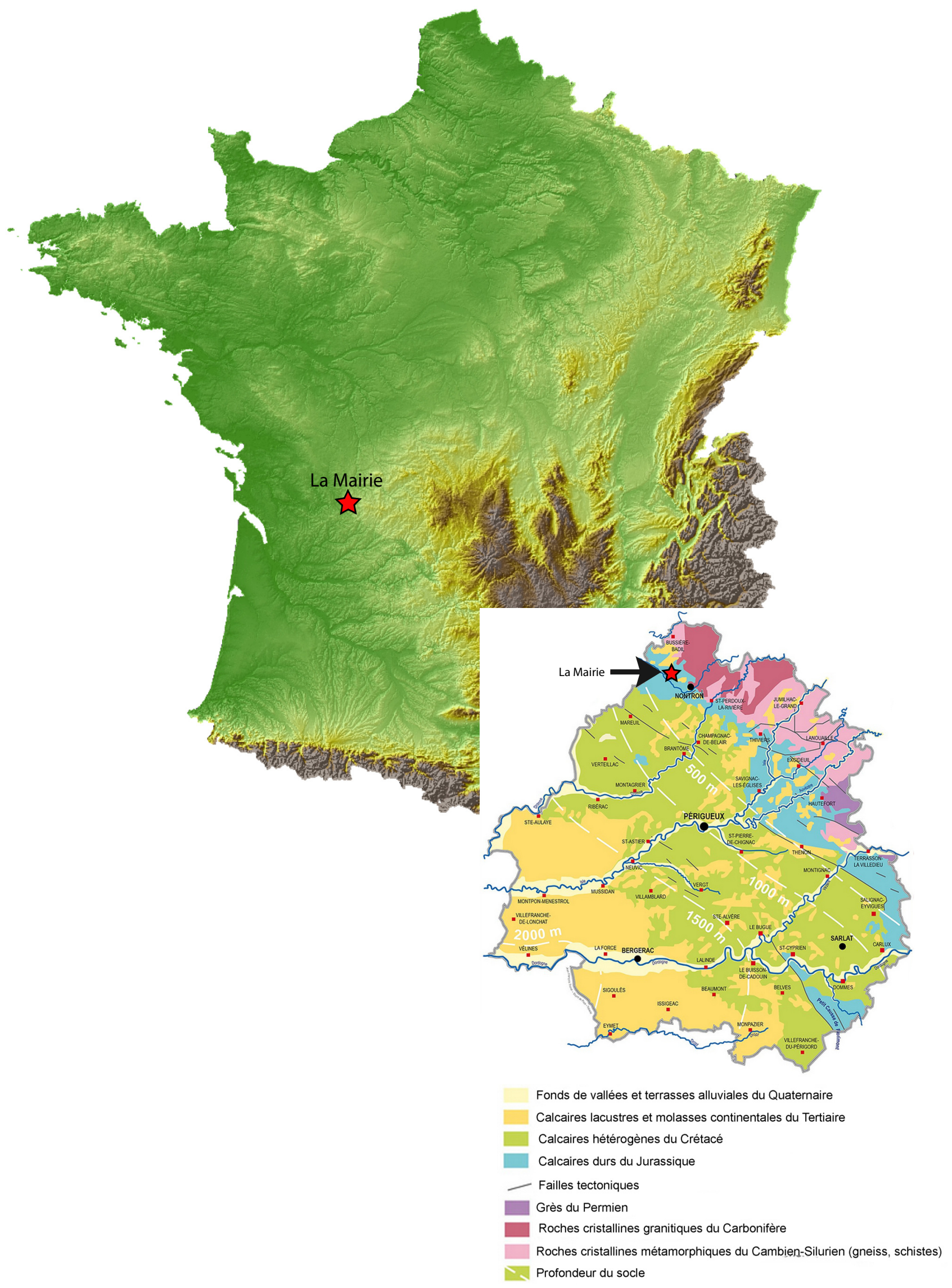

\section{- FIGURE 1 -}

Situation de la grotte de la Mairie en France (DAO P. Paillet) et carte géologique de la Dordogne, $\odot$ Esprit de Pays - Topacki (https://i0.wp.com/espritdepays.com/dorLocation of the cave of La Mairie in France and geological map of Dordogne dogne/wp-content/uploads/2015/04/cartographie-dordogne-geologie.jpg) 


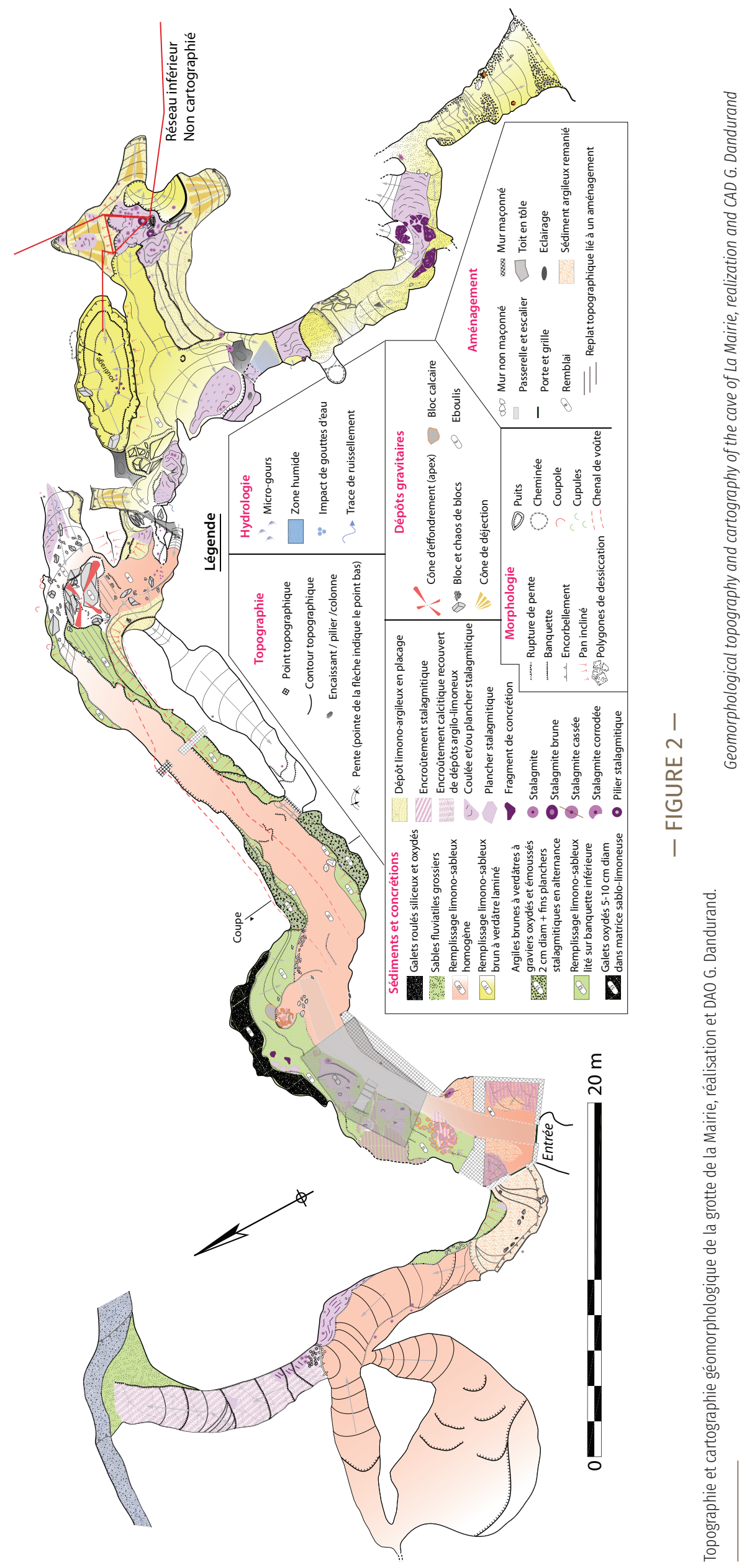




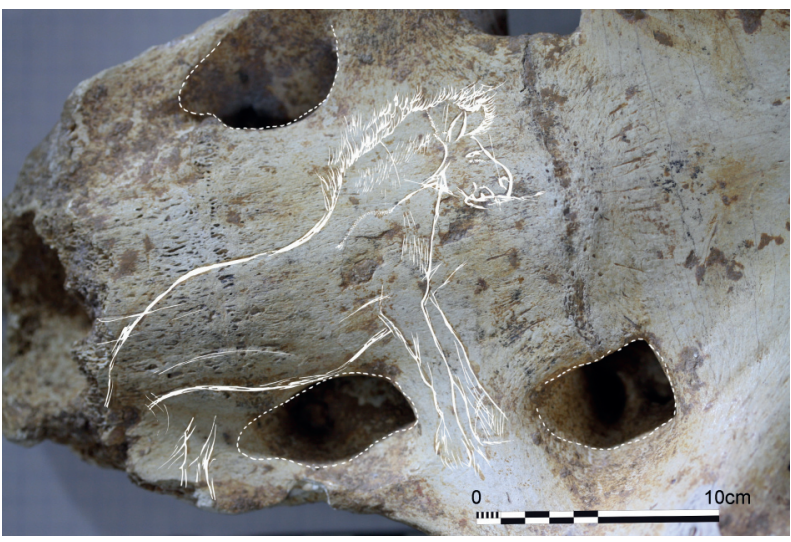

des œuvres gravées, faites par D. Peyrony, sont confirmées le 20 septembre par Louis Capitan qui en réalise également des relevés ${ }^{5}$, en l'absence de $\mathrm{H}$. Breuil et d'É. Cartailhac ${ }^{6}$ La grotte est fermée quelques jours plus tard par un mur maçonné et une clôture à claire-voie (fig.4).

Mais l'étude de la grotte reste profondément attachée à une personnalité locale, Pierre Bourrinet, instituteur de Teyjat depuis 1893 (Warembourg 2017). Après avoir fouillé sans succès dans la partie profonde de la cavité (à une quarantaine de mètres de l'entrée, près d'un secteur de soutirage), puis à une trentaine de mètres sous de gros blocs au bout de la galerie sèche, là où É. Perrier du Carne acheva l'une de ses tranchées larges et profondes, et enfin au droit de la cascade où le sol avait déjà été fouillé également par Perrier du Carne, P. Bourrinet ouvre à la fin de l'année 1904, à la demande de L. Capitan et H. Breuil, une importante fouille dans l'épais remplissage qui court de l'entrée de la grotte au pied de la cascade stalagmitique sur environ 12 mètres de longueur (Capitan et al. 1908). Sous un éboulis détritique stérile volumineux (couche F), constitué essentiellement de blocailles issues de la désagrégation de l'encaissant rocheux et de colluvions limonoargileux, il met au jour deux couches magdaléniennes, une couche supérieure ( $D$ et E) attribuée au Magdalénien supérieur récent, qui repose sur un dallage assez continu de plaques de stalagmites (C) et une couche inférieure (A et B) attribuée au Magdalénien supérieur ancien (contemporaine de celle l'abri Mège à $200 \mathrm{~m}$ de là) (fig. 5). Si la séquence n'atteint qu'un mètre d'épaisseur tout au plus contre la cascade stalagmitique, elle dépasse les 4 mètres au niveau de l'entrée. Ses fouilles, auxquelles participent épisodiquement D. Peyrony et A. Darpeix, le gen-

[5] « Le seul moyen de reproduction me paraît être celui que j'ai employé : le calque avec du papier de soie en suivant les traits que la pression du doigt fait apparaitre sur le papier et en complétant ensuite les traits qui n'ont pas pu venir même ainsi. C'est fort long. J'ai mis presque une journée pour faire ainsi les 9 bêtes mais avec une exactitude servile et -l y aura encore à vérifier sur place le dessin définitif. Ni estampage, ni photo ne peuvent rien donner au moins d'après mes essais. Je réessayerai ultérieurement. » (Capitan, correspondance à Henri Breuil, s.d.).

[6] Un court article publié le 1er octobre 1903 dans le journal L'Union nontronnaise et signé d'un certain Pierre des Grillaudes (un pseudonyme selon le marquis de Fayolle) met en doute l'authenticité préhistorique des gravures. L'auteur y livre le court récit de ses aventures dans la grotte en 1871 avec quelques camarades dont un aurait « . tracé sur le rocher, avec son vieux canif, des lignes assez grossières qui pouvaient représenter un bœu ou un cheval ou tout autre bête ». Si cet article éveilla les esprits les plus suspicieux y compris parmi les préhistoriens (Adrien de Mortillet notamment et l'un de ses fidèles amis Martial Imbert), il constitue pour nous la confirmation que la grotte de la Mairie était régulièrement fréquentée avant sa découverte officielle comme l'attestent les innombrables graffitis qui couvrent seulement le sommet de la cascade stalagmitique (panneau F) et une toute petite partie de la dalle voisine aux bisons (panneau D).

\section{FIGURE 3}

Sacrum de cheval gravé d'un cheval, photo et relevé P. Paillet.

Engraved sacrum of horse with a horse, picture and tracing P. Paillet

dre de Bourrinet, sont conduites parallèlement aux fouilles de l'abri Mège (Warembourg 2017 - p. 85). Les fouilles de la Mairie, régulièrement visitées par les préhistoriens et le public, s'achèvent en 1913, après la construction de la nouvelle porte d'entrée (fig.6) et à l'épuisement complet du gisement? La partie antérieure de l'entrée, sous le seuil de l'ancienne clôture surmontée par 4 mètres de sédiments, est entièrement décaissée et élargie entre les mois d'août 1912 et mai 1913. L'intérêt archéologique de ces importants terrassements semble secondaire (absence de publications notables hormis celle de 1929). Ce sont peut-être les objets découverts lors de ces opérations tardives qui ont été vendus en 1927 et 1928 au Field Museum de Chicago avec quelques autres provenant des premières fouilles. P. Bourrinet finance en partie ses recherches en vendant le mobilier qu'il découvre à Mège et dans une moindre mesure à la Mairie (dès 1908) au Musée des antiquités nationales. Les ventes au profit du Field Museum de Chicago sont plus tardives (1927 et 1928).

C'est à l'occasion des travaux de P. Bourrinet et notamment dans les premiers mois de la fouille (vraisemblablement avant mai 1905), que les trois autres blocs pariétaux gravés sont découverts (panneaux dénommés A, B et C) (Capitan et al. 1912 - p. 509). Ils sont complètement dégagés en août 1905 et ce sont 24 nouvelles gravures animales (cervidés, bisons, chevaux, ours) qui sont découvertes et qui portent à 40 le nombre de représentations relevées à ce jour (BSHAP 1905, T.XXXII, p. 373-374). Le corpus actuel de la grotte s'élève à 55 représentations, toutes figuratives. Il s'agit de 17 rennes, 10 chevaux, 9 indéterminés, 8 cerfs, 6 aurochs, 3 bisons et deux ours. Les dispositions entre les deux grands ensembles sont assez équilibrées : 31 à gauche ( 8 sur le panneau A, 10 sur le B, 13 sur le C) et 24 à droite ( 9 sur le $D, 3$ sur le E et 12 sur le F).

La longue monographie de 1908 (Capitan et al. 1908) constitue l'une des rares sources d'informations détaillées sur la fouille, sur la nature du site, sur sa stratigraphie notamment et sur les découvertes effectuées (faune, industrie lithique, industrie osseuse, art mobilier). Cette monographie précède évidemment les terrassements pour la construction de la porte que nous venons d'évoquer. Nous reviendrons sur cet article qui contient des informations intéressantes pour le sujet qui nous occupe,

[7] Avec une interruption entre 1908 et 1912, années pendant lesquelles P. Bourrinet fouille à l'abri Mège et à la Tabaterie. 


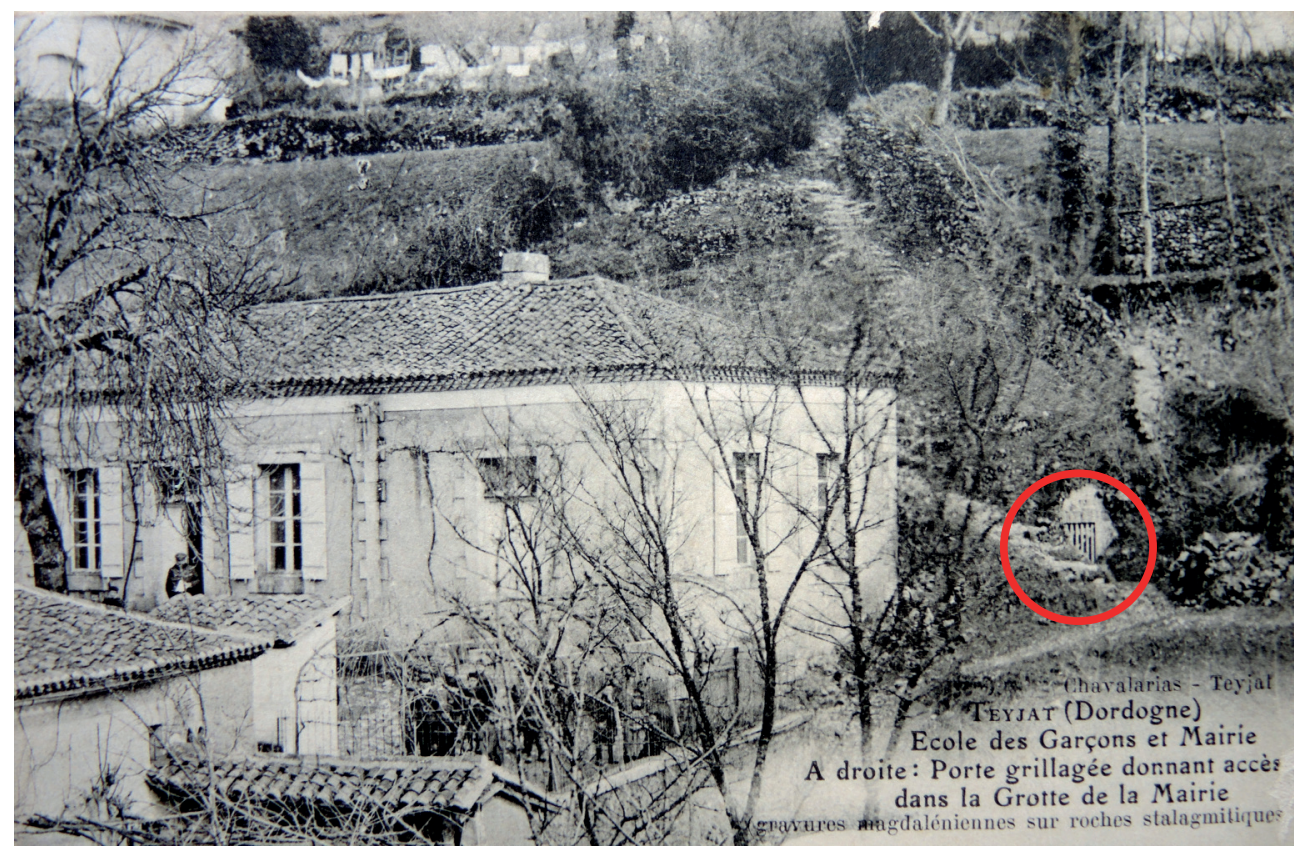

\section{FIGURE 4}

Entrée de la grotte de la Mairie avant 1912, carte postale ancienne «Chavalarias, Teyjat ».

Entrance of the cave before 1912 , old postcard " Chavalarias, Teyjat ».

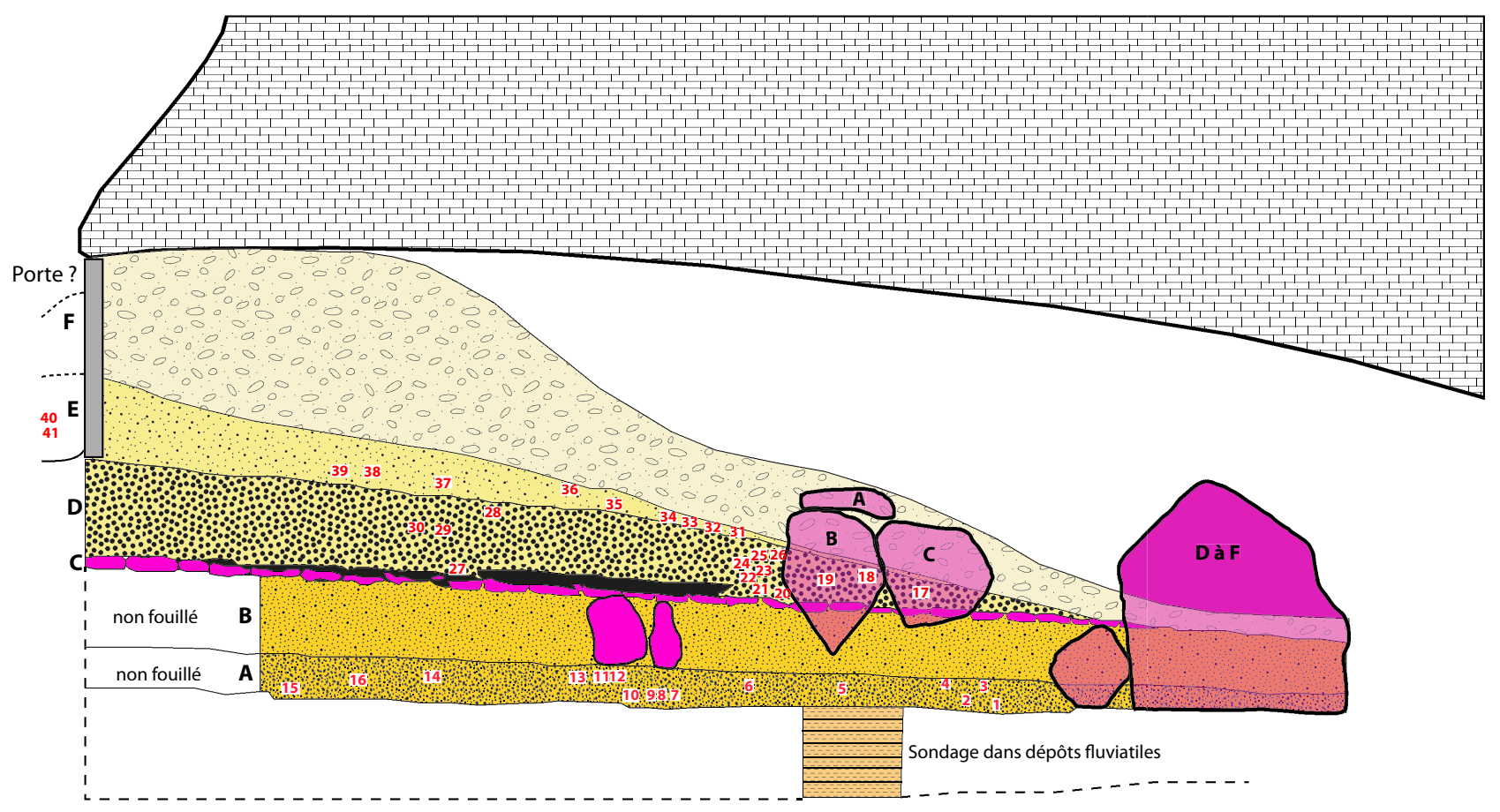

A. Couche archéologique inférieure reposant sur un sol de sable, d'argile et de petits graviers fluviatiles et de stalagmite.

B. Partie supérieure, stérile, de l'assise inférieure.

C. Dallage en plaques de stalagmite supportant $D$.

D. Partie intérieure de la couche supérieure.

E. Partie supérieure de la même couche.

F. Remplissage détritique stérile.

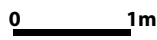

\section{- FIGURE 5 -}

Coupe stratigraphique de la grotte de la Mairie (fouilles et relevés P. Bourrinet), DAO E. et P. Paillet.
Stratigraphic view of the cave (excavations and tracings P. Bourrinet), CAD E. and P. Paillet. 


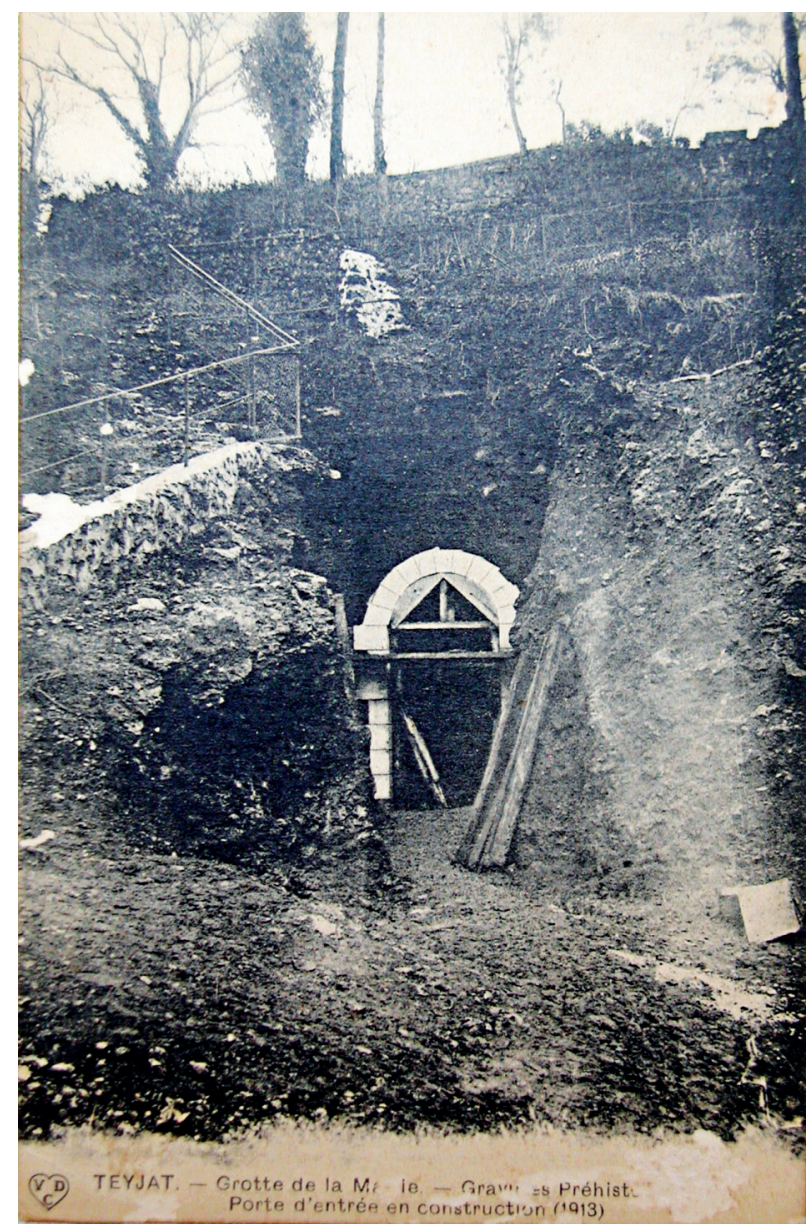

celui de la fragmentation des supports de calcite du dispositif pariétal.

L'étude et le relevé des œuvres gravées ${ }^{8}$ sont conduits par H. Breuil, avec l'aide de D. Peyrony et P. Bourrinet, entre les mois d'octobre 1904 et septembre 1905. La première publication détaillée de l'art pariétal de la Mairie (découvertes Peyrony et Bourrinet) doit attendre 1912 (Capitan et al. 1912) et la 14e session du Congrès international d'Anthropologie et d'Archéologie préhistorique tenue à Genève. Elle porte à la connaissance de la communauté scientifique internationale et du grand public l'extraordinaire qualité graphique et expressive des œuvres pariétales de la Mairie.

Des relevés de $\mathrm{H}$. Breuil, nous ne disposons aujourd'hui que des mises au propre à la plume conservées à la Bibliothèque Centrale du Muséum national d'Histoire naturelle. Elles sont réalisées sur un épais papier à partir des esquisses au crayon gras sur papier cristal. Comme pour de nombreux autres sites qu'il a étudié, H. Breuil a choisi les sujets qu'il souhaitait mettre en valeur et a volontairement minoré les superpositions et les entrelacements de représentations. Ses relevés sont sélectifs. Les figures sont isolées, sans référence au support, au relief, ou aux altérations de la surface.

[8] Nous ne savons pas ce que sont devenus les premiers calques des 9 animaux identifiés sur les 3 panneaux de la coulée de calcite principale signalés dans la 1ère publication à l'Académie et réalisés en septembre 1903 par D. Peyrony, puis les autres relevés effectués par L. Capitan le 20 septembre 1903, lors de sa première visite dans la grotte.

\section{FIGURE 6}

Construction de la porte d'entrée (1913), carte postale ancienne « Chavalarias, Teyjat $»$.

The construction of the entrance door (1913), old postcard «Chavalarias, Teyjat ».

Dès la découverte des gravures et surtout à partir de 1913 et la construction de la grande porte d'entrée, la grotte de la Mairie est largement ouverte aux visites (BSHAP 1905, Vol. XXXII, séance du 27 mai, p. 274) sous la conduite de P. Bourrinet jusqu'à sa retraite en 1924. Les clés de la grotte sont ensuite confiées à la famille Lagrange, père et fils, de 1925 à 1990. La conservation de la grotte et notamment de ses gravures et de leur support eut à souffrir durant ces décennies $^{9}$ des conditions de visites à la fois rudimentaires et très peu contrôlées. D'après plusieurs témoignages que nous avons recueillis auprès de la population de Teyjat, les visites s'effectuaient, il y a peu de temps encore, dans toute la cavité, y compris dans ses parties les plus profondes, hors champ graphique, souvent sans accompagnement et sans surveillance.

À l'occasion d'épisodes humides que nous ne sommes pas parvenus à dater avec précision, des écoulements eurent lieu sur plusieurs panneaux ornés, notamment le plancher ou panneau A (fig.7), dont une partie des représentations relevées et publiées en 1912 (cheval et renne) a disparu sous un voile de calcite opaque, sans qu'aucune précaution ne soit prise pour détourner ou drainer ces ruissellements. Un système de drainage artisanal sous la forme de petites tranchées ceinturant les dalles réalisées par C. Barrière dans les années 1960 a permis provisoirement de détourner l'eau des œuvres gravées. Mais des écoulements réguliers lors des épisodes humides

[9] «... il y a lieu de prendre des mesures pour la conservation des gravures d'un bloc. » (Journal de D. Peyrony, 13 juin 1929). 

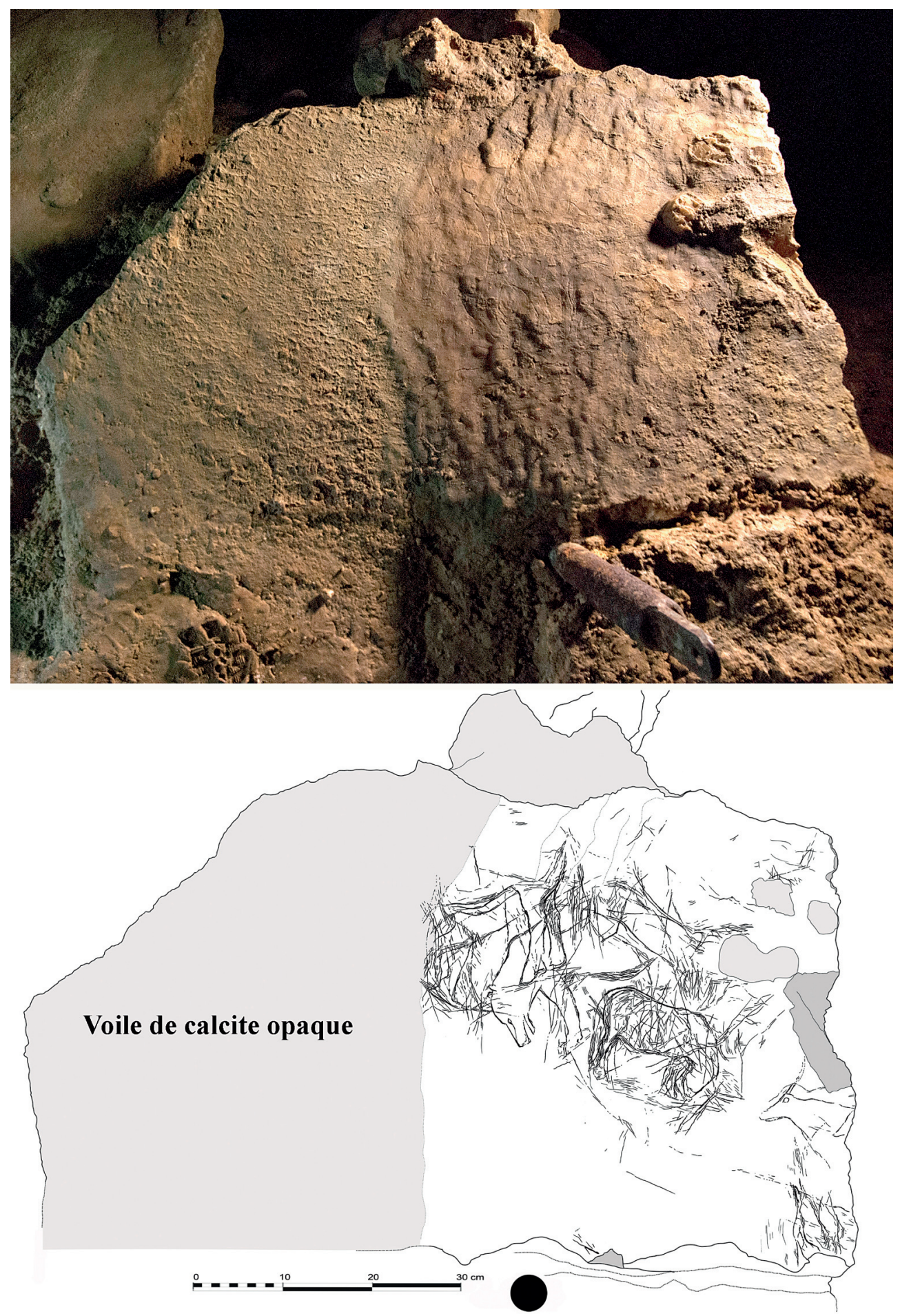

\section{FIGURE 7}

Panneau (ou dalle) A partiellement occulté par une coulée de calcite opaque, photo J.-C. Domenech (MNHN), relevé E. et P. Paillet.

Panel A, partially occulted by calcite, picture I.-C. Domenech (MNHN), tracing E. and P. Paillet.

sont encore très présents. Une calcitation importante affecte les sédiments au-dessus des panneaux A et C, à l'emplacement de l'actuelle dalle E et au gauche de la cascade et du panneau D. Sur le panneau C, à l'emplacement de l'avant-train du grand cerf, des déjections de chauve-souris, qui tardèrent à être nettoyées, ont définitivement dégradé la calcite par dissolution acide et contribué à la disparition de nombreuses gravures (Barrière 1968, p. 2) (fig. 8). Ces déjections semblent avoir été remarquées très tôt. En octobre 1931 D. Peyrony en visite dans la grotte note d'ailleurs que « ... les chauvessouris ne s'accrochent plus au-dessus du bloc gravé. » (Journal de D. Peyrony, 19 octobre 1931).
Vers 1966, jugeant que les relevés de H. Breuil offraient des défauts de détails, dont il dresse la liste exhaustive (échelles diverses, dissociation des figures, relevés inexacts, incomplets ou déformés), Claude Barrière entreprend de nouveaux relevés graphiques par calques directs du dispositif pariétal dont il précise qu'ils « ... n’ont pas la prétention d'être parfaits ni absolument complets, certaines parties de surfaces couvertes de stries désordonnées mais sans figures animalières n'ont pas été relevées. » (Barrière 1968 - p. 2). Il propose également des raccords entre dalles (notamment les panneaux E et F) et pense pouvoir reconstruire toute la cascade et retrouver des morceaux manquants. 


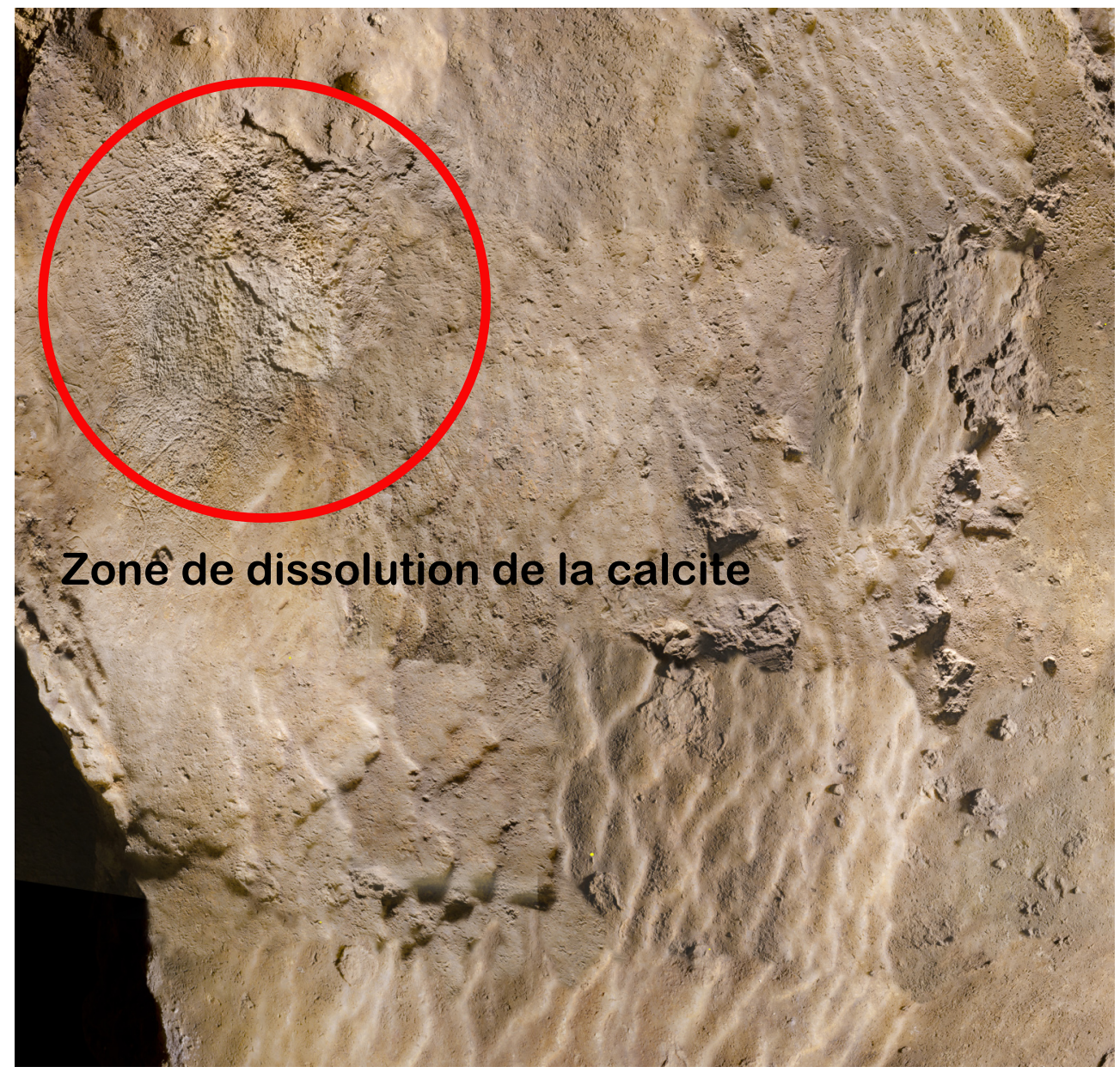

\section{FIGURE 8}

Dissolution de la calcite sur une partie du panneau (ou dalle) C, photo J.-C. Domenech (MNHN)

Calcite dissolution of a part of the panel C, picture J.-C. Domenech (MNHN).

Ce travail sera effectué par Norbert Aujoulat - à partir des relevés de Breuil - pour l'Atlas des grottes ornées publié en 1984. On y note cependant quelques erreurs de positionnement de figures (Aujoulat 1984 - p. 232-235) ${ }^{10}$. Éprouvant des difficultés à photographier les supports de calcite du fait de leur translucidité, Claude Barrière fait réaliser des empreintes au silicone-caoutchouc de plusieurs dalles, notamment du panneau A portant le petit ours complet. Le moulage au plâtre lui révèle une nouvelle représentation incomplète de cheval associée à l'ours qu'il publie quelques années plus tard (Barrière 1972). Le bloc D aux bisons et à l'ours acéphale fit également l'objet d'un moulage en octobre 1984 sous contrôle du LRMH pour être présenté au colloque international de Périgueux en 1984 et ensuite exposé au Musée d'Aquitaine (Bordeaux). Au final, cette première expérience de relevés de $\mathrm{Cl}$. Barrière ne tire avantage que des quelques remontages graphiques proposés, la qualité du rendu et sa fidélité n'étant pas toujours au rendez-vous comme le concède l'auteur luimême.
[10] II s'agit des 4 cerfs délicatement incisés au droit de la dalle C, relevés par Breuil après avoir clivé une épaisse couche de calcite qui les recouvrait, que Barrière et Aujoulat ne retrouvent pas et qu'ils supposent être masqués par la coulée de calcite qui a recouvert la partie droite du panneau A (cheval et renne) et la partie droite du panneau B. Pourtant Barrière avait bien remarqué et relevé l'un des cerfs réduit à ses lignes essentielles. A l'occasion du PCR, nous avons retrouvé et relevé ce petit groupe de cervidés à peine visible.
En 1973, il semble que Christian Archambeau (DRAC Aquitaine) et Gilbert Boldron (Agence départementale des Bâtiments de France) ont réalisé des travaux de relevés et de photos des gravures, mais nous n'en avons pas retrouvé la trace.

C'est enfin en 2012, sous notre responsabilité, que débute un Projet Collectif de Recherche (PCR) intitulé « Peuplements et cultures à la fin du Tardiglaciaire dans le Nord du Périgord, entre Dronne et Tardoire » dans la programmation duquel s'inscrit l'étude renouvelée et transdisciplinaire de la grotte de la Mairie, de son art pariétal évidemment, mais aussi des séries découvertes lors des fouilles Bourrinet et Darpeix, conservées notamment au Musée d'Archéologie Nationale (MAN) et au Musée de l'Homme. Lors de ce programme, achevé en 2017, de nouveaux relevés graphiques (relevés indirects sur supports photographiques sans contacts avec le support) (fig.9), photographiques et photogrammétriques (réalisation d'un modèle numérique de terrain 3D par le cabinet Perazio Engineering) ont été réalisés, ainsi qu'une étude taphonomique détaillée des supports de calcite (fig. 10) et une étude géologique et géomorphologique complète de la cavité (fig.2). Un constat de l'état sanitaire des supports stalagmitiques, précis et objectif, a également été dressé à l'occasion de ces recherches qui feront l'objet d'une prochaine monographie. 


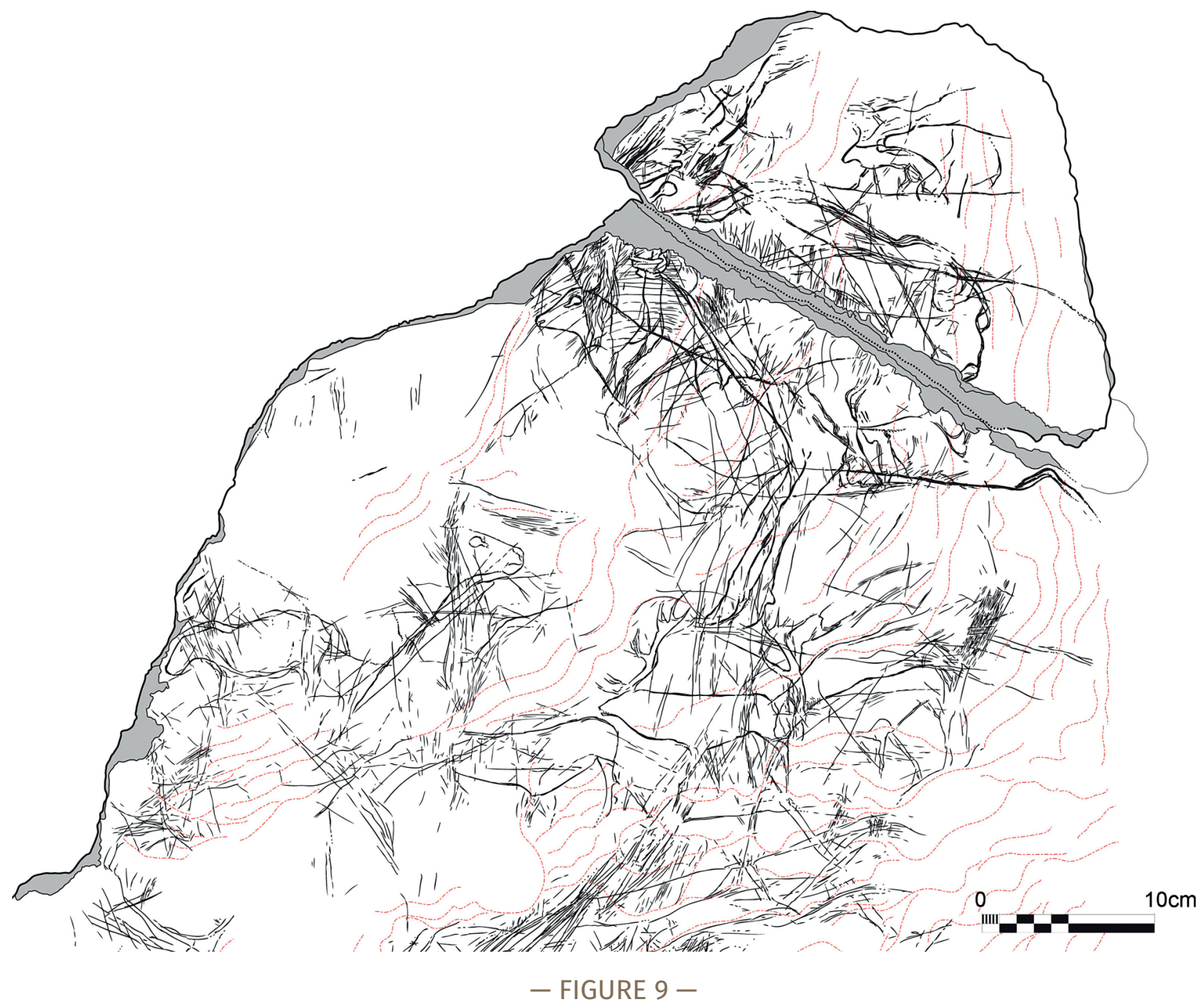

Relevé graphique de la partie supérieure du panneau (ou dalle) B, relevé E. et

Graphic tracing of the upper part of panel B, tracing E. and P. Paillet. P. Paillet.

\section{Des travaux à répétition et d'incessants aménagements}

Les premiers travaux qui affectent la grotte de la Mairie, encore discrète dans le paysage, sont les constructions de la mairie et de l'école. En mai 1878, l'entrée de la grotte au niveau des voûtes (« qui ont à cet endroit 4 à 5 mètres de hauteur $»^{11}$ est plus largement dévoilée à la faveur des travaux et du creusement d'une partie de la falaise pour adosser les bâtiments. L'architecte responsable du chantier, ignorant la présence de cette cavité pourtant déjà connue dans le pays ${ }^{12}$, fait reculer la construction d'environ 1,50 mètre par crainte d'effondrements et de travaux couteux (Warembourg 2017 - p. 44 ; Roth-Giraldez 2014, Vol.2, p. 30 ; Paillet (dir.) 2014 - p. 158).

[11] Extrait de la délibération du Conseil municipal de Teyjat du 12 mai 1878 qui constitue la première mention officielle de la grotte. La taille de la voûte indiquée dans le texte est certainement exagérée.

[12] « Ne croyant pas que ces constructions s'étendraient si avant dans le rocher du coteau, [on] ne songea pas à faire observer à cet architecte que des grottes immenses se trouvaient là. » (Délibération du Conseil municipal de Teyjat du 12 mai 1878.
Les premiers grands terrassements dans la cavité, alors en cours de fouilles sous la direction de P. Bourrinet, ont lieu bien plus tard entre les mois d'août 1912 et mai 1913. Il s'agit d'extraire des mètres cubes de sédiments sur une hauteur de 4 mètres et plusieurs mètres de long pour construire une véritable porte (fig. 11). L'accès à la cavité, qui appartient maintenant à l'État et qui est classée au titre des Monuments historiques depuis le 4 avril 1910, doit être facilité et sa sécurité assurée par divers aménagements comme la construction de murs, le creusement d'une profonde tranchée d'accès, la construction d'une porte monumentale et de barrages intérieurs (Warembourg 2017 - p. 77-80). La grotte parait enfin efficacement protégée en mai 1913. Denis Peyrony apporte quelques précisions sur ces premiers grands travaux: "Allé à Teyjat voir les fouilles de Bourrinet. Les fouilles de la grotte de la Mairie sont terminées. Elles ont fourni peu de choses. On construit un mur très épais à mortier de sable et de chaux avec une porte en voûte, pour fermer la galerie des gravures et soutenir la voûte de la grotte qui n'est pas solide. On fait également un mur à gauche pour fermer la galerie humide. Une balustrade a été construite tout autour pour éviter les accidents. Les travaux seront terminés sous peu. » (Journal de D. Peyrony, 

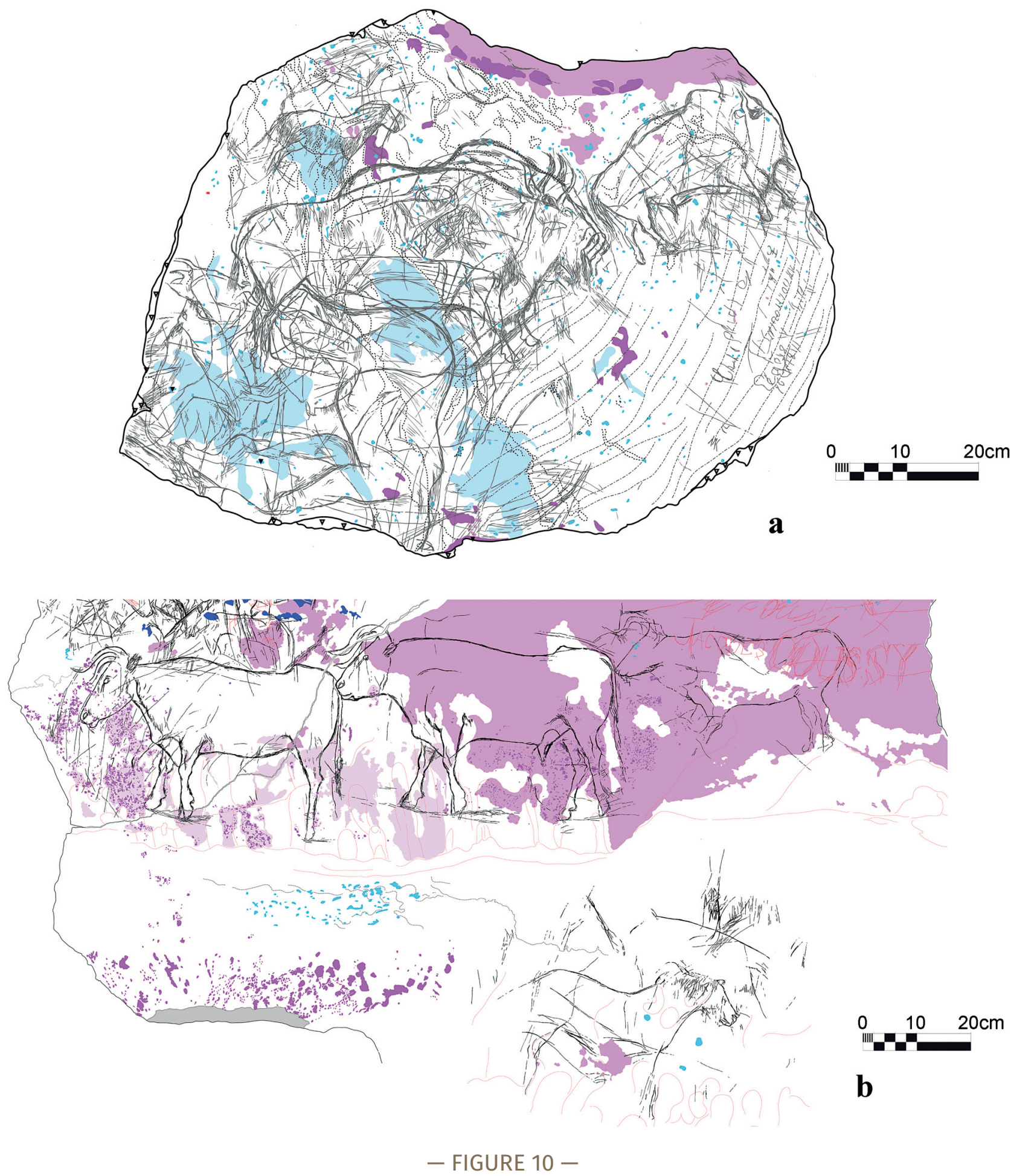

Relevé graphique et cartographie taphonomique du panneau (ou dalle) D (a) et d'une partie de la cascade F (b), relevé E. et P. Paillet et cartographie S. Konik et P. Paillet.

20 avril 1913). Mais l'ablation de l'éboulis d'entrée, la clôture artificielle et les changements de géométrie de cette cavité de taille modeste ouverte au sud en pied de falaise, ainsi que les considérables aménagements dont elle a fait l'objet, ne sont pas sans conséquence sur la conservation de la grotte, avec notamment « ... un impact accentué du climat extérieur qui diminue le confinement
Graphic tracing and taphonomic cartography of panel D and part of panel F, tracing E. and P. Paillet and cartography S. Konik and P. Paillet.

naturel et induit des phénomènes thermo-hydriques à l'origine de dégradations ou de menaces sur les vestiges » (Bourges 2015 - p. 131-132).

L'abandon progressif de la cavité à une exploitation touristique non contrôlée inquiète les autorités qui tardent à intervenir. En décembre 1957, un éboulement d'une à deux tonnes de pierres au-dessus de la porte 


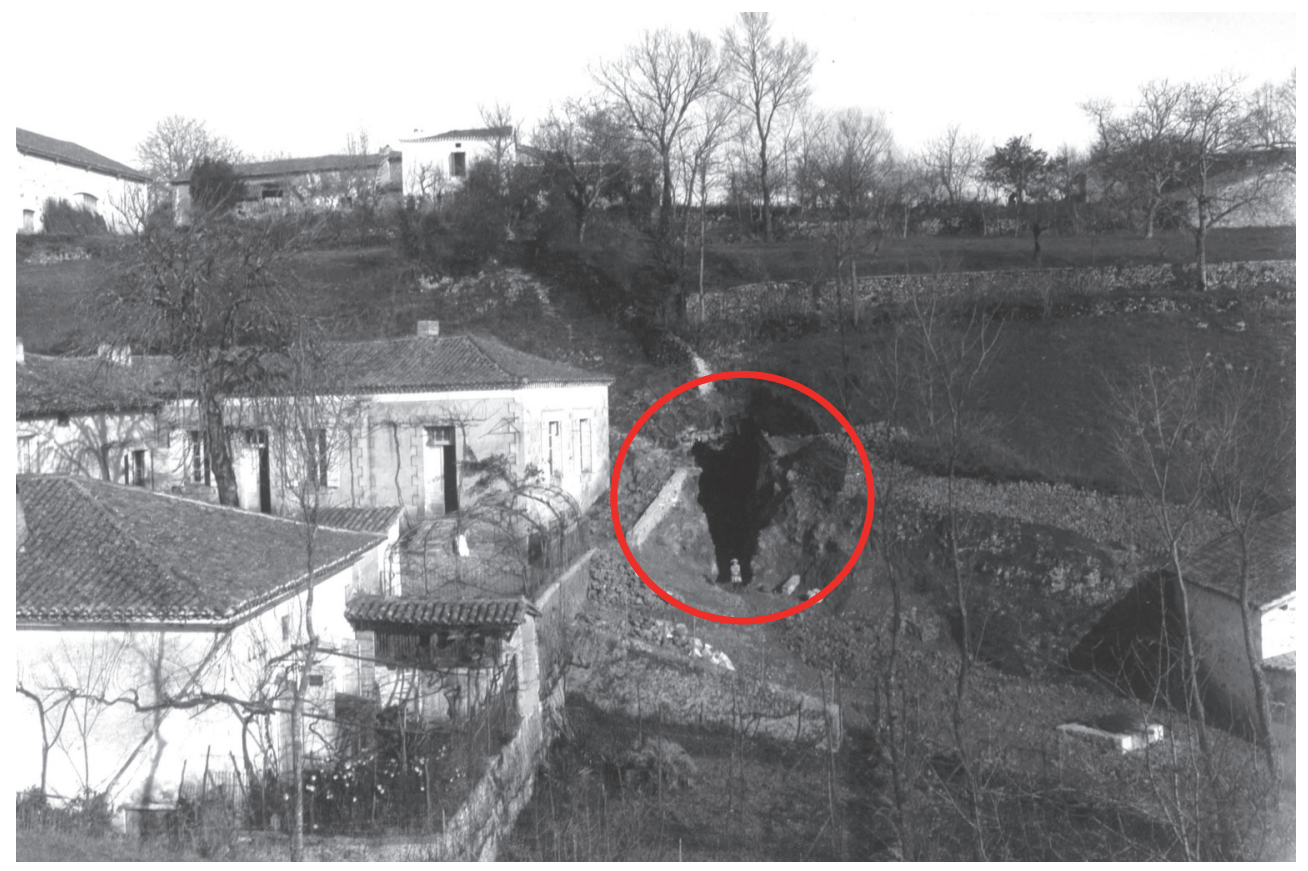

\section{FIGURE 11}

Entrée de la grotte de la Mairie après décaissement complet et avant la construction de la porte (fin 1912 - début 1913), photo D. Peyrony (fonds Peyrony, MNP).

Entrance of the cave after the entire disbursement and the building of the door (end of 1912 beginning of 1913), picture D. Peyrony.

d'entrée conduit à des travaux de déblaiement par les Bâtiments de France. C'est à partir des années 1960 que des travaux pour assurer la restauration, la protection et les aménagements (Courrier Alain Roussot à François Bordes du 27 novembre 1963) pour les visites sont conseillés par Alain Roussot, puis pour certains réalisés sous la conduite des architectes des Bâtiments de France. Ce n'est que le début d'un long cycle de nouveaux aménagements et de travaux d'entretien.

Devant la porte d'entrée de la grotte construite en 1913, et dont on ne sait pas si elle isolait ou non la grotte des échanges thermiques avec l'extérieur, est édifié dans les années 1970, à l'initiative de Max Sarradet, alors Conservateur régional des monuments historiques, un sas d'entrée aux murs maçonnés qui supportent une dalle en béton et qui englobe également l'entrée de la galerie de gauche. Il est fermé par une porte en bronze et crée une zone tampon d'environ 3 mètres de profondeur dont la fonction est indispensable pour atténuer le gradient thermique et hydrique entre l'extérieur et la zone ornée. Par ailleurs, la mise en liaison des deux galeries apporte l'effet régulateur de la galerie humide non ornée (Brunet et Vidal 1989 - p. 181). Mais des éboulements de la voûte entrainent la fermeture temporaire de la grotte au public.

D'autres aménagements sont réalisés au début des années 1980 comme la pose d'une plaque de couverture intérieure de $30 \mathrm{~m}^{2}$ (de type onduline) entre la voûte et les blocs gravés destinée à protéger les dalles des eaux d'infiltration et des déjections de chauve-souris ${ }^{13}$, la pose d'un caillebotis métallique au sol pour faciliter la progression et d'un emmarchement également en fer pour

[13] Cette toiture, renforcée par une autre plaque en polycarbonate transparente posée après la chute d'un bloc en 2006, est toujours soutenue par la structure métallique ancienne, repeinte à une date indéterminée (présence de gouttes de peintures sur la cascade gravée), mais atteinte de nombreux points de rouille. Les poutres horizontales ont été équipées de gouttières en PVC sur lesquelles se condense selon les périodes beaucoup d'humidité et qui facilitent l'accroche des chauves-souris (présence de déjections). accéder en partie haute des blocs, la fixation (directement dans le support de calcite) d'une rambarde en cuivre supplémentaire pour protéger le panneau des aurochs et l'installation d'un nouveau réseau électrique « ...approprié, avec cheminement et circuits ponctuels pour chaque partie gravée... » (Brunet et Vidal 1989, p. 181), y compris jusqu'au fond de la grotte. Si la fée électricité fit jadis des miracles, elle a considérablement défiguré la grotte et notamment sa partie ornée. Des câbles et des gaines électriques sont tirés un peu partout dans les sédiments, maquillées par de la glaise et des remblais, et ce jusque sous les dalles gravées, dont l'assise argileuse a été creusée pour l'occasion. Des interrupteurs sont scellés au ciment tout près des dalles. La pose de plusieurs boîtes lumineuses projetant les relevés Breuil comme aide à la lecture date également de cette époque. Ces boîtes étaient solidement fixées sur des piquets métalliques (en fer) au mieux accrochés sur la toiture intérieure ou enfoncés et cimentés tantôt dans la paroi calcaire, tantôt insérés entre les dalles gravées et parfois même chevillés dans la calcite $^{14}$ (fig. 12). Du côté des services compétents (Service Départemental de l'Architecture et du Patrimoine de Dordogne et Conservation Régionale des Monuments Historiques d'Aquitaine), on semble vouloir s'occuper de la grotte, de sa sécurité et de celle des visiteurs, ainsi que de la valorisation, mais les solutions de fortune sont apportées au détriment de l'esthétique et surtout, bien involontairement, de la conservation.

Dans les années 1990, un nouvel état des lieux de la grotte de la Mairie est dressé par des agents du Laboratoire de Recherche des Monuments Historiques (LRMH, Champssur-Marne), de la Caisse nationale des monuments historiques et des sites (devenue aujourd'hui le Centre des Monuments Nationaux) et du Musée national de Préhistoire. Il pointe à nouveau de graves problèmes de conservation comme des risques d'effondrement, une

[14] Elles furent enlevées au début des années 2000 


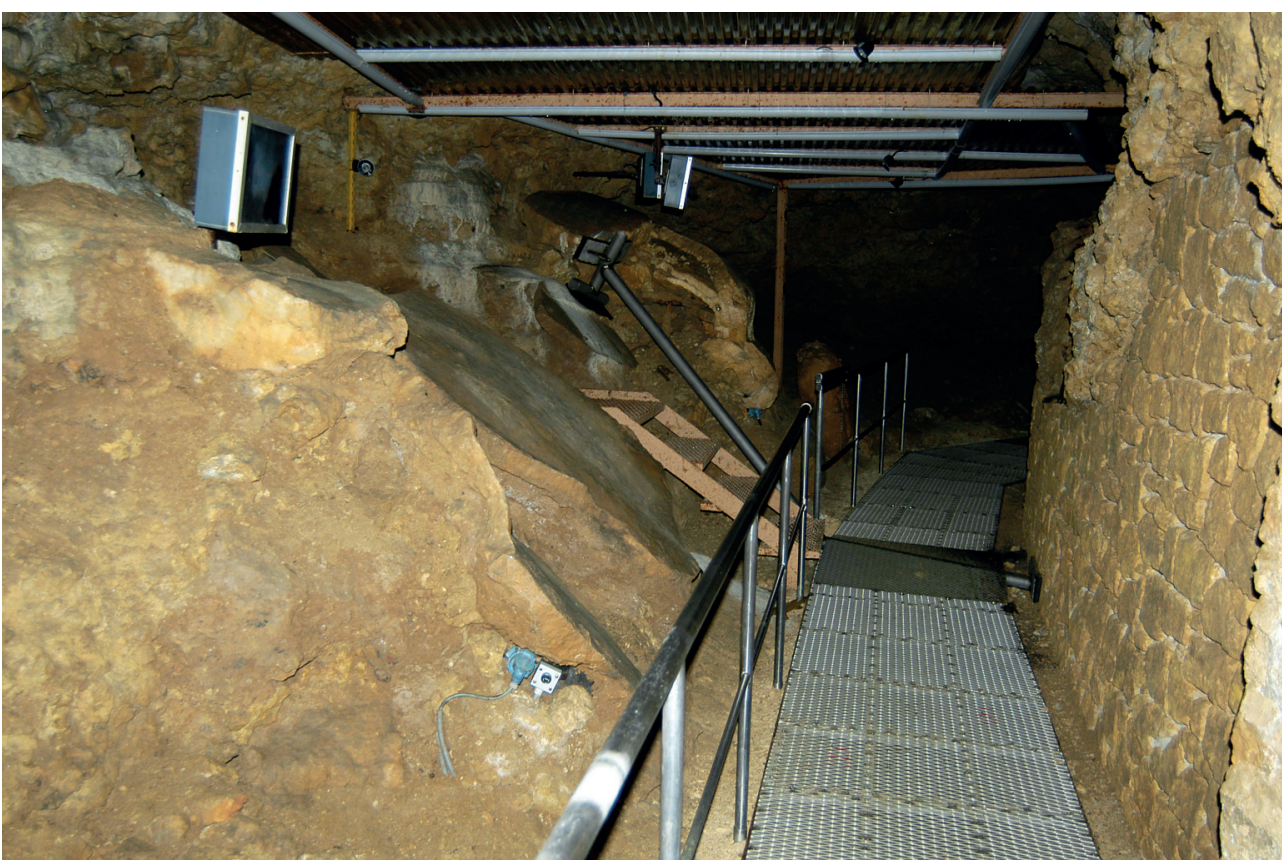

\section{FIGURE 12}

Aménagements à l'intérieur de la grotte (vers 2000), photo Ph. Jugie (fonds MNP).

Facilities inside the cave (around 2000), picture Ph. Jugie.

saturation en humidité et un encrassement général des gravures sur les supports horizontaux. Ce constat d'état conduit à de nouvelles interventions techniques par le SDAP de Dordogne et la CRMH (pose d'une rambarde et d'un caillebotis en inox à la place des équipements anciens, nettoyage, curage, remblaiement, puis réduction du cheminement public, construction d'un mur de soutènement au pied de la paroi droite particulièrement fragile, ouverture de deux bouches de ventilation hautes et basses dans le mur d'entrée du sas pour recréer un courant de convection naturelle contrôlé par des portes à glissières permettant d'en régler le débit, suppression des éclairages artificiels en fond de grottes, etc.). La nécessité d'assurer un contrôle photographique ${ }^{15}$. et un suivi microclimatique réguliers et sur plusieurs cycles annuels s'impose ${ }^{16}$. En effet, malgré toutes les mesures prises, on observe de nouvelles dégradations par les déjections de chauves-souris et par les écoulements d'eau, temporaires mais importants.

La fragmentation et la supposée mobilité des supports pariétaux redeviennent aussi une problématique centrale. On considère qu'hormis la cascade stalagmitique, les trois autres dalles sont en situation aléatoire. Des raccords ou des recollements entre plaques dispersées ou trouvées en fouilles sont probables. La présentation d'un ensemble stalagmitique entièrement recomposé tel qu'il devait être au Paléolithique est suggérée mais elle impliquerait une évacuation, un traitement et un tamisage des abondants déblais subsistant dans la grotte qui n'ont pas encore été réalisés à ce jour. Nous avons procédé en 2016 à une

[15] Dans le cadre de notre PCR une importante couverture photographique a été effectuée pour chaque panneau et chaque entité graphique. Par ailleurs, nous disposons également, outre un modèle numérique de terrain 3D en haute résolution réalisé en 2013, d'une cartographie taphonomique de très haute précision de tous les supports exécutée par Stéphane Konik et nous-même en plusieurs étapes de 2012 à 2015 (Paillet (dir.) 2012 à 2015).

[16] Dans le cadre du PCR un suivi des températures en continu a été effectué par Dominique Genty de 2012 à 2014 (Genty et Régnier 2013 - p. 173-179 ; Konik et al. 2014, p. 8593) et l'état microclimatique du site a pu être mesuré sur 24 h en août 2015 (températures, activité volumique en radon, humidité relative, teneur en $\mathrm{CO}^{2}$, teneur en $\mathrm{O}^{2}$, pression barométrique) par François Bourges (Bourges 2015 - p. 119-132). première opération de tamisage d'une partie des déblais accumulés dans le sas d'entrée de la grotte (Paillet et ManEstier 2016a - p. 164). Elle a permis de récolter quelques éléments d'industrie lithique magdalénienne (lamelles à dos) et d'assez nombreux petits fragments de calcite provenant vraisemblablement du démantèlement de la cascade et des blocs et peut-être même du dallage remarqué par P. Bourrinet à la base de la couche supérieure. Aucune de ces pièces ne porte des gravures ou des traces intentionnelles anciennes. Par ailleurs, à l'occasion des différents travaux effectués dans le cadre du PCR aucun lambeau de couches en place n'a été localisé. Les bases sur lesquelles repose cette hypothèse de la dispersion des principaux blocs demeurent cependant assez théoriques. Au début des années 1990, la grotte est fermée provisoirement au public. En 1994, des intrusions dans la cavité sont constatées par le deuxième accès à l'autre extrémité du réseau. Deux grilles sont rapidement installées pour condamner les entrées secondaires. En 1997, c'est au tour de l'édifice stalagmitique de montrer des signes de faiblesses, avec un risque d'affaissement et de basculement de la dalle aux bisons (D) ainsi que d'un élargissement de la fissure qui lézarde la cascade. Mais une comparaison de la fissure actuelle avec des documents photographiques anciens et des documents d'archives ne confirme pas cette hypothèse. La fissure semble stable et nous n'avons observé à l'œil nu aucune évolution particulière durant nos séjours dans la cavité lors de nos travaux de relevés. Après avoir craint les excès d'humidité, les experts s'inquiètent à présent de l'assèchement de la grotte et du désagrègement du remplissage argileux qui soutient la cascade. Sur avis de l'Architecte des bâtiments de France et de la Commission nationale des monuments historiques (6ème section) une étude est diligentée qui conclut que la statique de l'ensemble des blocs a été affectée surtout par les fouilles anciennes, qu'ils sont en équilibre précaire et qu'il convient rapidement d'apporter des solutions d'étaiement provisoire. Une longue béquille en acier inox, reposant contre le mur maçonné de la paroi 
droite, est installée et un berceau métallique couvert d'une épaisse contre plaque de caoutchouc permet de supporter le bloc D. La pose de témoins indique que le bloc a poursuivi sa lente chute avant d'être stabilisé par l'étai. Ces dispositifs envahissants mais nécessaires sont encore en place aujourd'hui, ainsi qu'une partie des anciens aménagements dont la dégradation (rouille notamment) n'est pas sans effet sur la conservation des gravures. Les études géologiques et climatologiques appelées de ses vœux par la CNMH ont été engagées dans le cadre de notre PCR entre 2013 et 2017. De 1994 à 2006, la grotte est épisodiquement (un jour par semaine en juillet et août) ouverte au public sous la conduite de Cécile Gizardin ${ }^{17}$. En 2006, la chute d'un nouveau bloc provenant de la voûte à proximité du champ orné entraine la fermeture immédiate de la cavité pour des raisons sanitaires et de sécurité.

Le public, privé de la grotte originale, peut toujours visiter la salle d'exposition permanente (Centre d'interprétation Pierre Bourrinet) inaugurée en 1999 et dont le programme a été entièrement conçu à partir de 1993 par un comité scientifique constitué de préhistoriens et présidé par c. Barrière. Cette salle, qui offre un panorama complet de la préhistoire, de la protohistoire et de l'époque galloromaine en Périgord septentrional, vient de se doter de nouveaux supports pédagogiques (panneaux didactiques, visites virtuelles de la grotte en 3D et nouveaux moulages.

\section{L'art de la Mairie : art mobile ou pariétal ?}

Ce constat est sans appel mais il ne dit pas précisément qui, de la nature ou de l'homme, porte la responsabilité principale des dégradations constatées dans la grotte de la Mairie, et en premier lieu du démantèlement de l'édifice stalagmitique (Gernigon 2011). Il est également difficile de préciser dans quelle mesure les fouilles, la fréquentation de la grotte ou les remaniements plus récents ont déstabilisé les blocs et modifié leur disposition initiale. Seule la dalle $\mathrm{E}$ a quitté très tôt sa place originelle, déplacée et présentée à divers endroits dans la grotte, à l'entrée en position semi-verticale (fig. 13) ou couchée aujourd'hui au sol entre les panneaux C et D. Enfin, ce constat n'indique pas si la disposition que nous connaissons aujourd'hui est le fait des Magdaléniens euxmêmes ou bien si elle était identique avant même que les Préhistoriques ne viennent y graver. Par ailleurs, nous savons que les derniers de ces Magdaléniens, les seconds occupants du site, ont aménagé leur sol par un pavage de plaquettes de calcite : « Ces fragments étaient disposés à peu près horizontalement bout à bout, ou tout au moins très près les uns des autres, parfois superposés, sur toute la largeur comprise entre les blocs gravés et la paroi opposée ; ils étaient plus clairsemés le long de celle-ci, tandis qu'en face, ils avaient été plus ou moins concrétionnés ... » (Capitan et al. 1908 - p. 157). L'édifice stalagmitique en constituait à coup sûr le gisement et nous en avons récupérés quelques-uns dans une partie

[17] Guide-conférencière pour le CMN et pour la RMN-Grand Palais et animatrice au service d'action culturelle et éducative du Musée national de Préhistoire. De 1994 à 1999, pour la communauté de communes, elle a accompagné la conception et l'aménagement de l'espace Pierre Bourrinet. Nous lui devons notamment la découverte d'une gravure qui complète le dispositif pariétal, une partie du museau du grand ours (accidentellement) acéphale du panneau D, discrètement logée sur le bord du panneau E sous le petit renne. des déblais encore présents dans le sas d'entrée. Il semble illusoire d'aller beaucoup plus loin pour pointer le ou les responsables et in fine pour tenter de reconstituer l'hypothétique décor d'origine dont aucun argument ne permet à l'heure actuelle d'en mesurer le degré d'intégrité.

D'ailleurs, il n'est pas improbable que le décor pariétal qui se déploie sous nos yeux soit à peu de choses près celui qu'exécutèrent les Magdaléniens, y compris dans la disposition actuelle des trois premiers panneaux (Paillet et Man-Estier 2015, 2016b). La question de la mobilité d'une partie du dispositif (les dalles A, B et C notamment) a également été soulevée pour proposer un statut « mixte » original à l'art de la grotte de la Mairie, entre pariétal et mobilier, au cœur d'un habitat d'entrée de grotte (Leroi Gourhan 1971 ; Tosello 2003 ; Paillet et al. 2015). La dalle D aux bisons est un fragment d'épais plancher stalagmitique totalement dissocié d'un plancher initial dont on voit encore l'accroche en paroi. Sa mobilité sous l'effet gravitaire est probablement consécutive à un soutirage ou une rétraction des sédiments qui le supportaient. Mais si ces dalles sont effectivement « transportables $»^{18}$ et qu'elles ont été « ... prélevées par les Magdaléniens parmi les concrétions, et disposées ensuite dans la partie antérieure de la cavité ... » (Tosello 2003 p. 473), cela n'en fait pas pour autant un art mobile par destination. Et ce n'est pas davantage «... un sanctuaire de plaquettes, placé dans l'habitat [...] des nappes de figures dont l'ordre originel est perdu ... » (Leroi-Gourhan 1971 - p. 281-282). L'étude du dispositif gravé et l'analyse de l'organisation des figures et de leurs orientations nous conduisent à suggérer l'hypothèse que les gravures ont été réalisées après l'effondrement partiel de cette partie de l'édifice stalagmitique et non avant. L'idée selon laquelle ce sont «... les nouveaux venus [Magdaléniens] qui remanièrent [les morceaux de cascade], redressant les uns le long de la paroi gauche, en laissant d'autres à plat dans leur situation originelle. » (Capitan et al. 1912 - p. 499) manque d'arguments objectifs face aux observations géomorphologiques. L'étude faite par G. Dandurand (2014, p. 73-87) et l'étude du massif stalagmitique proposée par S. Konik et D. Genty ${ }^{19}$ indiquent que la disposition oblique à sub-verticale des deux dalles stalagmitiques (B et C) est bien le fait d'un déplacement ou d'une remobilisation de la structure (originellement horizontale à sub-horizontale). Ces dalles montrent deux types de surface, une surface ondulée dont les vagues caractérisent un écoulement assez soutenu en pente douce, et une surface plane avec de nombreux espaces intercristallins triangulaires

[18] «... la taille des dalles B (L. $145 \mathrm{~cm}$, L. $108 \mathrm{~cm}$, ép. moyenne $15 \mathrm{~cm}$ ) et C (L. $167 \mathrm{~cm}$, L. 133 $\mathrm{cm}$, ép. moyenne $15 \mathrm{~cm}$ ) est importante. On considère que la masse volumique de la calcite est d'environ 2,6-2,8 tonnes par m3. On peut donc estimer le poids de la dalle Bà plus de $400 \mathrm{~kg}$ et celui de la dalle Cà plus de $700 \mathrm{~kg}$. Il n'y a donc rien d'impossible au transport ou au déplacement collectif de tels blocs mais on s'éloigne sensiblement des formats connus dans l'art dit « mobilier » ... » (Paillet et al. 2015 - p. 436).

[19] En 2014, une reconstitution des principales étapes d'édification du dôme stalagmitique éventré a été proposée. Elle suggère l'existence d'au moins 6 phases de croissance séparées par des discontinuités argilo-détritiques et l'évidage d'un ancien support sédimentaire. Dans ce vide sous le dôme un concrétionnement postérieur est attesté par de petites stalactites et draperies. Le flanc du massif stalagmitique est marqué par des vagues d'érosion de type « coups de gouge » qui témoignent aussi d'un nouvel épisode de circulation des eaux dans la galerie (Konik et al. 2014, p. 85-87). Ce travail de reconstitution a permis également d'obtenir une date U/Th pour les phases récentes de concrétionnement sur l'un des blocs non orné abandonné dans les déblais. L'âge obtenu de $205 \mathrm{ka} \pm 2,5$ montre que le sommet du plancher s'est développé au cours du stade isotopique $7 \mathrm{~b}-7 \mathrm{c}$. D'autres dates seraient utiles pour mieux caler chronologiquement les différentes phases de croissance et mieux comprendre la mise en place de l'édifice (Konik et al. 2014 - p. 87). 


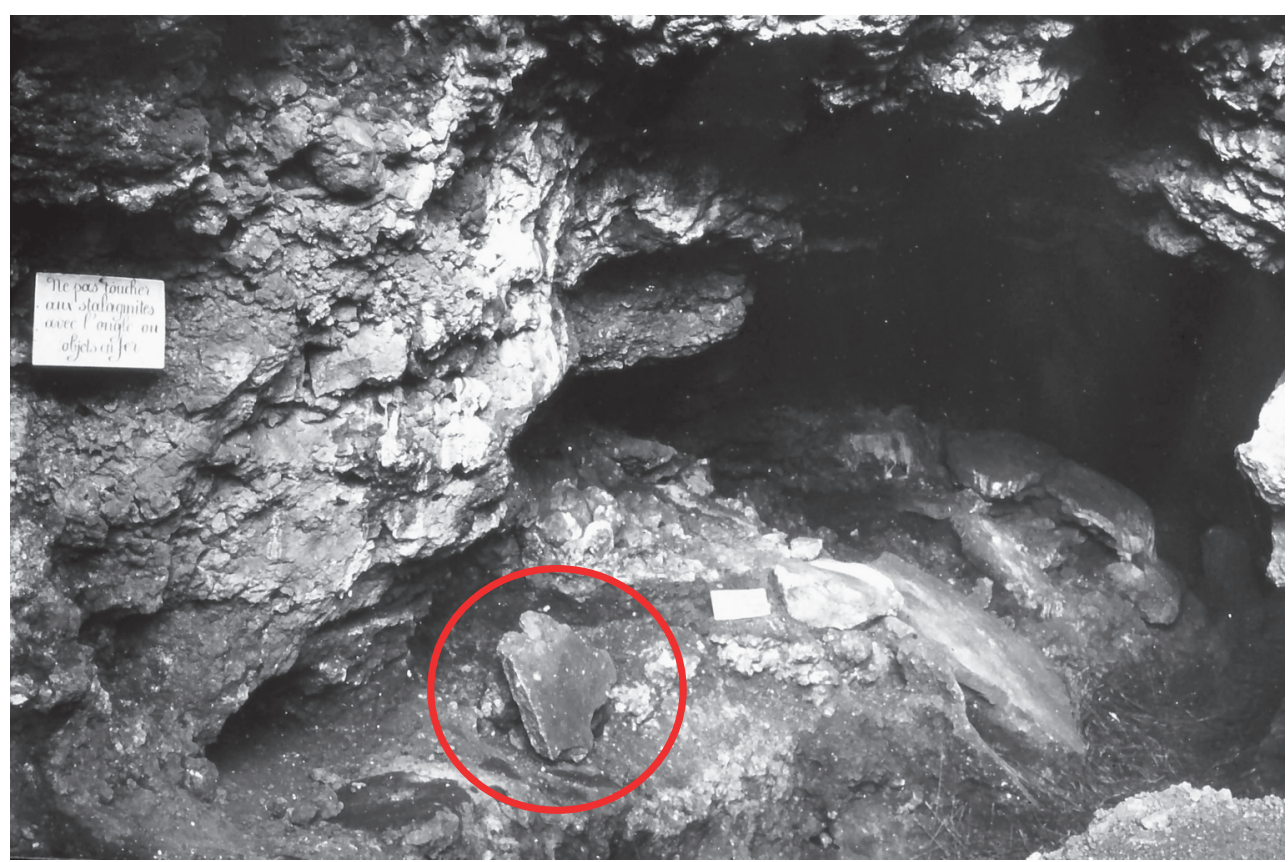

\section{FIGURE 13}

Position du panneau (ou dalle) $\mathrm{E}$ vers 1912 (?) à l'entrée de la grotte, photo D. Peyrony (fonds Peyrony, MNP).

Location of panel E around 1912(?) at the entrance of the cave, picture D. Peyrony.

millimétriques à infra-millimétriques qui peuvent correspondent à des zones à plat sur lesquelles le niveau d'eau est resté stable pendant de longues périodes » (Genty et Régnier 2012 - p. 136). Cette situation résulte pour une grande partie d'une dislocation naturelle ancienne d'un très vieil édifice, suite à une réactivation du réseau. " La présence de dépôts de décantation sur le dernier plancher, mais aussi l'ablation partielle du remplissage en dessous, sont des arguments qui militent en faveur d'une phase complexe de réactivation de la cavité fossile, par ennoiement partiel, autorisant une érosion du remplissage par fluage, sapement et soutirage, mais aussi des cassures de blocs ou du plancher stalagmitique » (Dandurand 2014 - p. 83).

\section{De l'art pariétal dans les musées}

Les cassures franches et visibles, parfois même assez fraîches, au niveau de la cascade et du bloc A, nous avaient fait croire, au début de notre recherche, à une possible reconstitution de l'édifice à partir des gros morceaux de planchers qui gisaient encore dans les déblais anciens (notamment à l'entrée et à droite de la

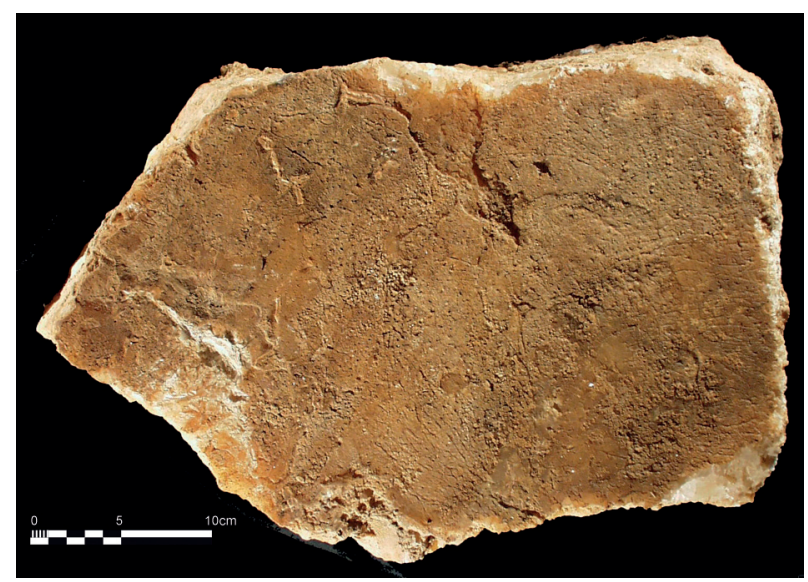

cascade). Nous connaissions l'emplacement originel de la dalle E qui avait pourtant pas mal voyagé et nous pouvions imaginer une aventure similaire aux compléments du panneau A. Mais aucun des fragments encore présents dans la grotte ne portait de gravure et ne s'adaptait aux panneaux en place, hormis un morceau de vieilles draperies que nous avons pu replacer au pied et à gauche de la cascade (panneau F). Nous apprenions en même temps qu'en 1999 N. Aujoulat et J.-J. Cleyet-Merle avaient extrait des déblais de la cavité un lourd fragment gravé d'un renne qui avait été transporté au Musée national de Préhistoire et intégré dans sa nouvelle muséographie (Mangier 2010-2011) (fig. 14). Il manquait bel et bien des morceaux de calcite pour compléter la cascade et peutêtre des pans de son iconographie mais aucun ne semblait être encore dans la grotte. Le long travail d'analyse des supports, de relecture et de relevé des gravures que nous avons effectué de 2012 à 2017 n'a pas été sans effet pour cette entreprise de reconstitution, particulièrement instructive.

\section{FIGURE 14}

Dalle de calcite gravée découverte par N. Aujoulat et J.-J. Cleyet-Merle en 1999 dans les anciens déblais de la grotte, photo Ph. Jugie (MNP).

Engraved calcite slab discovered by N. Aujoulat and J.-J. Cleyet-Merle in 1999 in the former archeological remains, picture Ph. Jugie. 


\section{Un sommet de cascade ébréché et son complément au Musée d'Archéologie nationale}

Au-dessus du panneau des aurochs (F), la partie haute de la cascade, légèrement inclinée, offre une surface de calcite fine en assez bon état de conservation, malgré quelques impacts récents de teinte claire et malgré les passages réitérés des premiers explorateurs de la grotte au XIXème siècle. Ce secteur peu accessible n'avait fait l'objet d'aucun relevé de la part de $\mathrm{H}$. Breuil et $\mathrm{Cl}$. Barrière. Pourtant dans ce vide iconographique ce sont des centaines, voire des milliers de traits enchevêtrés en palimpsestes que nous avons identifiés puis relevés. Mais, comme signalé plus haut, c'est surtout le roman des premières explorations qui s'y trouve conté à la pointe ou au tranchant métallique. Il a pu occulter des gravures plus anciennes que nous ne sommes pas parvenus à identifier précisément, même si certaines lignes droites ou courbes à section large et fond en $U$, ainsi que quelques rares raclages superficiels très patinés, rappellent les tracés magdaléniens. La composition circulaire restituée par Cl. Barrière et N. Aujoulat (Barrière 1968 ; Aujoulat 1984) a été à cette occasion complétée par la découverte fin 2012 dans le coin supérieur droit de la cascade, d'un grand aurochs mâle acéphale (Paillet et al. 2012, 2013, 2014), de 42 cm de long, disposé en miroir par rapport aux autres aurochs de la frise. À ses côtés, deux extrémités de pattes (sabots de chevaux ? ${ }^{20}$ gravés sous le petit bison mâle du panneau $D$, également en bord du support.) finement incisées sont placées en limite de support (fig. 15). Il manquait certes une tête à ce nouvel aurochs pariétal, peut-être totalement effacée par les innombrables graffitis et raclages modernes qui couvrent cette partie de la cascade, mais également, du fait d'une fracture de l'angle du support peu épais à cet endroit, l'extrémité de sa queue et de ses membres postérieurs, sous les jarrets. Une ligne de sol courrait par ailleurs sous les antérieurs. À la Mairie, nous avons dénombré une quinzaine d'animaux (chevaux, rennes, bisons et aurochs) sur les 55 recensés soigneusement appuyées sur des lignes de sol gravées parfois exécutées individuellement pour chaque membre. Lors de l'étude des séries d'art mobilier provenant des fouilles Bourrinet, le hasard nous fit retrouver au MAN une dalle de calcite inédite en deux fragments jointifs (sans provenance et numéro d'inventaire) $(\mathrm{L} .: 39,5 \mathrm{~cm} ; \mathrm{l}$. : $18 \mathrm{~cm}$; ép. maximale : 7,5 cm), conservée aux côtés d'autres morceaux de calcite plus petits. Son étude a permis de déterminer la présence, parmi des graffitis modernes, de deux extrémités de pattes postérieures terminées par des sabots reposant sur une longue ligne et enfin à l'arrière quelques traits en guise de toupillon. Nous avions entre les mains la modeste partie manquante de la cascade et du nouvel aurochs et nous pûmes en faire à distance un remontage photographique (fig. 15). Nous ignorons si ce morceau fragile a cédé sous les pas des premiers visiteurs de la grotte ou durant les fouilles Bourrinet. Peut-être même s'agit-il d'un élément évoqué par les fouilleurs : « des fragments de diverses figures qui n'ont pu être raccordées,

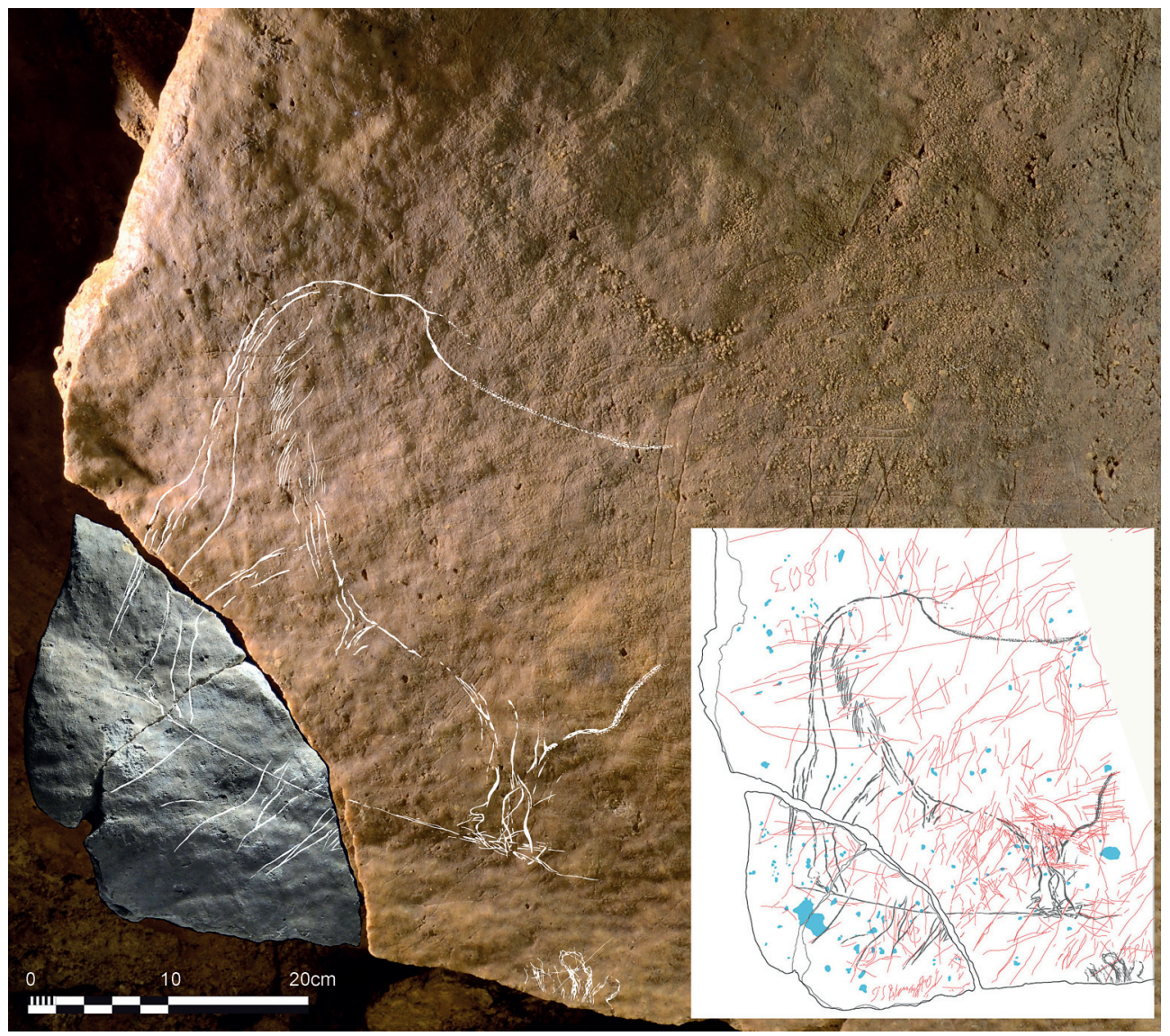

\section{FIGURE 15}

Remontage photographique et graphique de la partie supérieure droite de la cascade $F$ et de la dalle gravée conservée au MAN, photo et relevé E. et P. Paillet.

Reassembling of pictures and tracings of the upper right part of panel $F$ with the calcite slab from the MAN, picture and tracing E. and P. Paillet.

[20] Cette représentation segmentaire pourrait être associée aux tracés (fesse et queue?) gravés sous le petit bison mâle du panneau D, également en bord du support. 
dont l'un porte une patte mal faite. » (Capitan et al. 1912 p. 514). Désormais c'est donc un animal entier et totalement inédit qui complète le dispositif pariétal et sa construction circulaire. L'ironie du sort veut qu'il soit inscrit à la fois sur un support immeuble et mobile ! Nous envisageons d'effectuer une photogrammétrie à haute résolution du bloc et du secteur de la cascade portant l'aurochs afin d'en proposer un remontage virtuel beaucoup plus précis.

\section{Le panneau $E$ et son complément}

Cette trouvaille n'est pas sans rappeler celles qui avaient été faites autrefois par D. Peyrony et P. Bourrinet. Le premier avait découvert fin août - début septembre 1903 le dôme gravé et la plaque E presque détachée (L. : $90 \mathrm{~cm}$; l. : $63 \mathrm{~cm}$ ), sur laquelle se trouvaient trois rennes et un cheval auquel il manquait les pattes arrières. Le second retrouva celles-ci sur un petit bloc pendant ses fouilles en 1904 ou 1905. "Les jambes postérieures [d'un beau cheval] manquaient au moment où M. Peyrony le découvrit ainsi que les figures avoisinantes, mais M. Bourrinet a retrouvé le fragment détaché qui les portait dans la couche archéologique supérieure. » (Capitan et al. 1912 p. 504). Dans la monographie de 1908 les auteurs ne situent pas ce fragment au même endroit semble-t-il. « Un fragment de la figure d'un cheval gravé sur un des premiers blocs découverts, et comprenant ses sabots postérieurs, avait été recueilli au pied de la grande cascade, mais en ce point, l'assise archéologique, très pauvre, ne pouvait être définie avec précision. » (Capitan et al. 1908 - p. 172). Il s'agit du seul fragment assurément pariétal à avoir été découvert en stratigraphie. Il est présenté aujourd'hui avec la dalle d'où il est issu (fig. 16).

\section{Un autre morceau de la grotte au Musée national de Préhistoire}

Le bloc extrait de la grotte en 1999 et présenté au MNP, n'avait pas fait l'objet d'une étude poussée à l'exception d'une numérisation en 3D par C. Mangier (2010-2011). On ne sort pas souvent des vitrines du musée de tels objets lourds et encombrants (L. : $42 \mathrm{~cm} ; \mathrm{l}$ : : $28 \mathrm{~cm}$; ép. $\max : 26 \mathrm{~cm}$ ). Mais nous eûmes l'occasion d'en solliciter la consultation en 2014 dans le cadre du PCR. Il s'agit d'un fragment très épais d'un plancher stalagmitique dont la face principale est rigoureusement plane. Les observations à l'œil nu, l'analyse et le relevé somme toute très classiques que nous en avons effectués ont permis de compléter la tête de renne déjà connue, avec ses bois portés sur un micro-relief de la calcite, ainsi que d'identifier un arrière-train de cervidé (renne probable) doté d'une série de pattes, peut-être un indice d'animation, des stries, des raclages et des gerbes de traits (fig. 17). Les artistes de la Mairie nous ont habitués à l'expression du mouvement, soit par des attitudes dynamiques des membres, par des mises en scènes éthologiques ou par des artifices graphiques comme la multiplication des membres ou des profils (bison, cerf, cheval, renne, etc.). Ce bloc a été fortement percuté comme le montrent plusieurs plages d'impacts récents. Son épaisseur (près de $30 \mathrm{~cm}$ ), sa texture et son grain, la morphologie, la couleur et la taille des cristaux de calcite, ainsi que la présence d'un macro-cristal sur le bord gauche nous ont permis de le replacer dans son environnement pariétal. Il s'agit de la partie gauche du panneau A (fig. 18). Sa fracturation a pu être occasionnée lors des fouilles de P. Bourrinet. Le remplissage argileux sur lequel s'était formé le plancher a été en effet largement décaissé dans toute la partie vestibulaire de la grotte. Il y a fort à parier que les gravures de cette partie du plancher n'ont pas été aperçues lors des fouilles, avant que Breuil ne vienne effectuer ses relevés à partir du mois d'octobre 1904. Le support a été débité au moment du décaissage en y mettant certainement beaucoup d'énergie eu égard à l'épaisseur de matière. Le bloc a ensuite été rejeté avec d'autres (non ornés) dans les déblais.

À notre demande, Hugues Plisson en a réalisé une photogrammétrie qui pourrait être associée au modèle numérique de terrain 3D effectué par Perazio Engineering.

\section{Cliver la calcite ?}

À plusieurs reprises dès 1905, les auteurs évoquent des opérations de clivage des calcites. Nous nous sommes interrogés sur cette pratique, à laquelle se sont exercés P. Bourrinet, qui est le premier à remarquer que des traits plongent sous les nouvelles concrétions, puis L. Capitan, $H$. Breuil et D. Peyrony. Leurs effets sur la conservation et l'intégrité des œuvres ont dû être sensibles (Breuil et al. 1908 - p. 7). Lors de nos travaux dans la grotte, nous avons constaté à diverses reprises des traces en forme de coups de gouge dans des dépôts d'argile indurée subsistant sur quelques blocs, témoignages des méthodes expéditives de ce début de XXe siècle. Le clivage est différent du travail d'abrasion mené sur les calcites qui opacifient les peintures de la Grande Grotte d'Arcy-sur-Cure (Yonne) ou de Shulgan-Tash (Oural, Russie). Le clivage est l'opération qui consiste à fendre le corps minéral dans le sens naturel de ses couches. Cette opération mécanique pratiquée aux ciseaux ou aux pics vraisemblablement métalliques a été rendue possible dans certains endroits de la Mairie grâce à l'intercalation d'un enduit argileux très fins entre le support gravé et les nouvelles concrétions empêchant ainsi l'adhérence des deux concrétions. Ce n'est malheureusement pas le cas sous le voile de calcite opaque qui recouvre aujourd'hui toute la partie droite du panneau A, nous privant d'une partie importante d'un cheval et d'un renne si l'on en juge par les relevés de Breuil.

Après le départ des premiers Magdaléniens, et au moment de la mise en place du pavage sur une couche stérile par les derniers occupants de la grotte, un retour à des conditions climatiques apparemment plus tempérées et surtout beaucoup plus humides semblent avoir réactivé les ruissellements, notamment le long de la paroi gauche, en arrière du bloc gravé A. « Les concrétions qui en étaient résultées reliaient fortement ce dernier à la paroi, et le couvraient complètement sur 0 m. 01 d'épaisseur moyenne, descendant ensuite sur les blocs disposés obliquement jusqu'au pavage. Ce travail de concrétion semble en partie antérieur à la seconde phase d'occupation humaine ${ }^{21}$, mais il s'est continué durant qu'elle s'écoulait et même après [...] il y avait jusqu'à 5 feuillets stalagmitiques superposés à la dalle horizontale, qui a été dégagée par un travail de clivage que facilitait une intercalation très mince de sable argileux; ce travail a permis d'obtenir la " contre-empreinte naturelle » de certains dessins ... » (Capitan et al. 1908 -

[21] Ne serait-ce pas un argument chronologique en faveur d'une réalisation du dispositif pariétal par les premiers occupants de la cavité? 


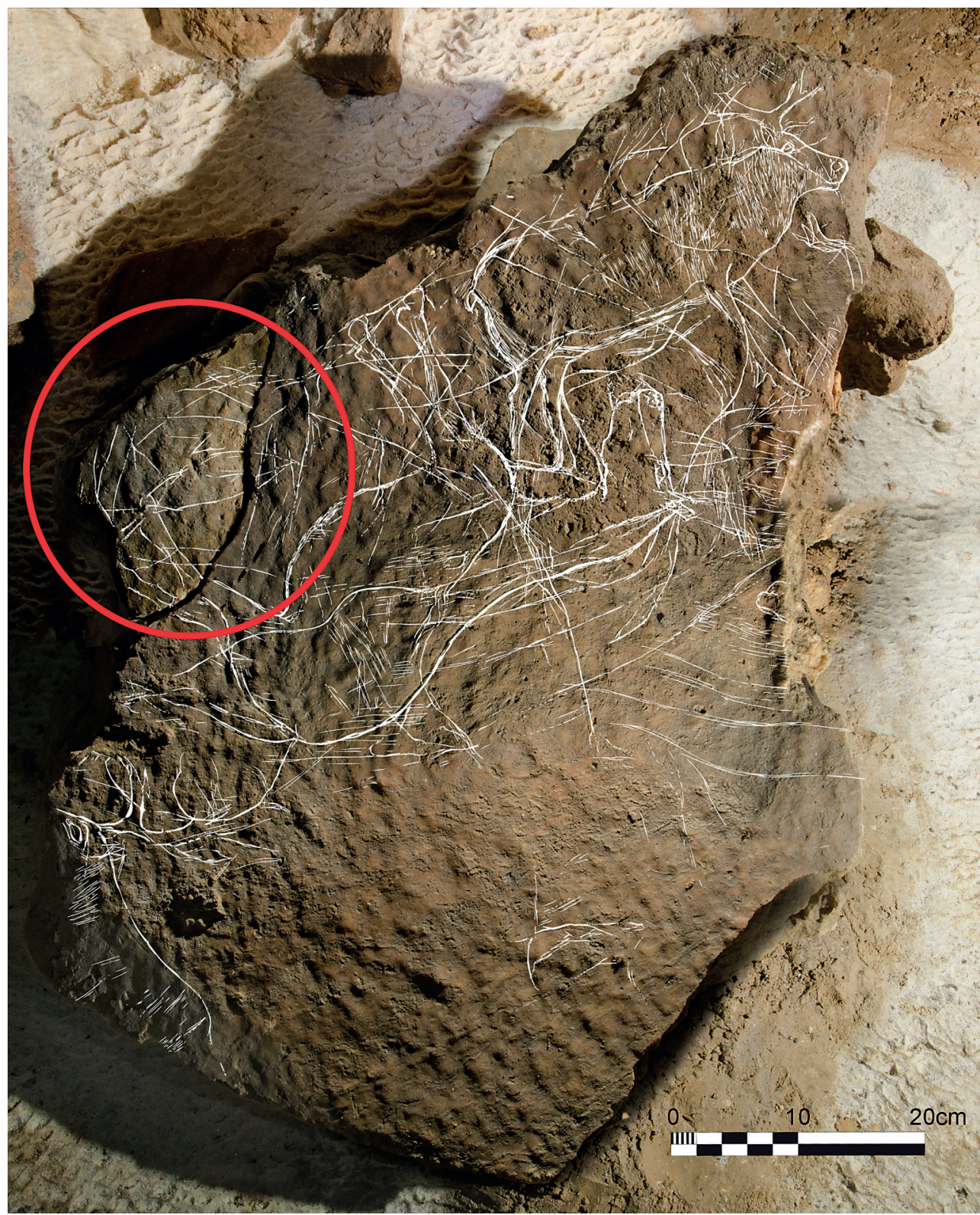

\section{FIGURE 16}

Panneau (ou dalle) E et situation du fragment découvert en stratigraphie par P. Bourrinet, photo J.-C. Domenech (MNHN) et relevé E. et P. Paillet.

Panel $E$ and localisation of the fragment discovered within the stratigraphy by $P$. bourrinet, picture J.-C. Domenech (MNHN) and tracing E. and P. Paillet.

p. 158). Il faut se débarrasser de ces concrétions sous lesquelles plongent des traits. "Une partie de celle-ci [cascade], recouverte par le remplissage, était encroutée de nouvelles couches de carbonate de chaux, tantôt très minces, tantôt épaisses de plusieurs centimètres; à coups de ciseaux et aussi avec des lavages énergiques et répétés et un brossage réitéré, nous avons pu extraire de dessous leur manteau calcaire des figures, qui en étaient complètement masquées, et qui se présentèrent, une fois dénudées de ce revêtement, avec une fraîcheur des traits qui nous ferait douter, si nous n'avions assisté, les uns après les autres, à l'apparition, sous une plaque soulevée par nous-même, d'un nouveau dessin aussi frais. " (Capitan et al. 1905 - p. 87). On décolle les calcites récentes à peu près partout où cela est nécessaire et possible : bloc A (Capitan et al. 1912 - p. 512-513) et la dalle C au moins (Capitan et al. 1912 - p. 509). La pratique des clivages nous permet de comprendre pourquoi les découvertes n'ont pas été réalisées en une fois. L'état des surfaces, leur recouvrement par des concrétions, des sédiments ou de l'argile gêne la lecture fine. «... Quant aux surfaces sim- plement enfouies dans le remplissage, des lavages et brossages énergiques ont eu raison des grains terreux et des incrustations légères qui en gênaient la lecture. » (Capitan et al. 1912 - 501). On est fort loin des précautions prises aujourd'hui dans les grottes ornées. Les quatre petits cerfs découverts par Breuil sur le bloc C à l'issue d'un clivage sont les figures que $\mathrm{Cl}$. Barrière et N. Aujoulat ne parvenaient pas à retrouver et qu'ils supposaient être cachées sous le voile opaque de concrétions qui recouvre la partie droite du bloc $\mathrm{B}$. Pourtant $\mathrm{Cl}$. Barrière avait bien relevé l'un de ces cerfs mais sans l'associer à ce groupe dont nous donnons ici un relevé (fig. 19).

\section{Une concrétion avec contre-empreinte au MAN}

Tous ces clivages ont soulevé et produit des plaques (moulages naturels) plus ou moins épaisses dont certaines portaient les négatifs des gravures qu'elles avaient recouvertes. Nous ignorons le sort qui fut réservé à toutes ces concrétions avec « contre-empreinte » (Breuil 


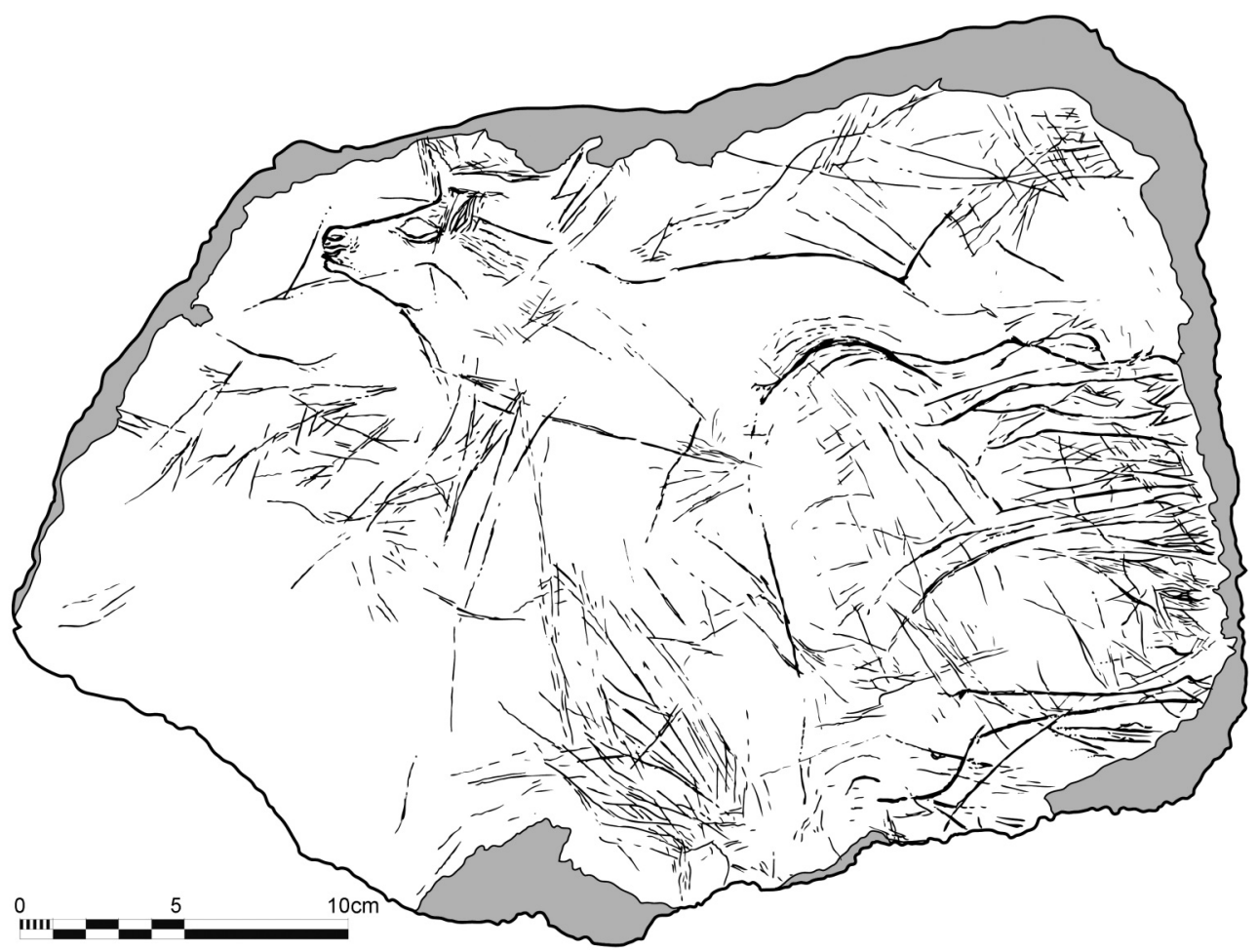

FIGURE 17

Dalle de calcite gravée découverte par N. Aujoulat et J.-J. Cleyet-Merle en 1999 dans les anciens déblais de la grotte, relevé P. Paillet.

Engraved calcite slab discovered by N. Aujoulat and J.-J. Cleyet-Merle in 1999 in the former archeological remains, tracing P. Paillet.

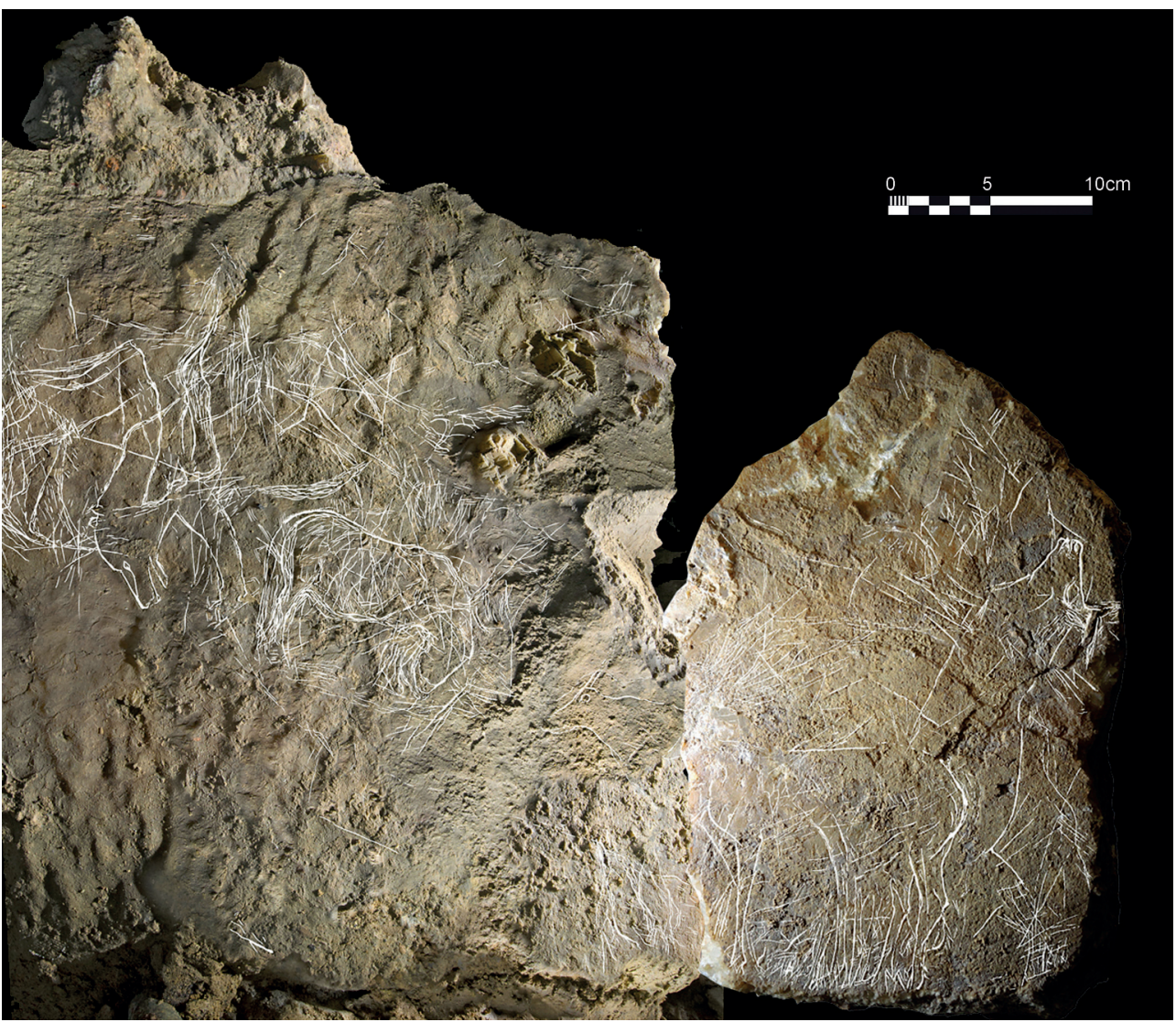

\section{FIGURE 18}

Remontage photographique et graphique du panneau (ou dalle) A et de la dalle de calcite gravée découverte par N. Aujoulat et J.-J. CleyetMerle en 1999 dans les anciens déblais de la grotte, photo J.-C. Domenech et P. Paillet et relevés $E$. et $P$. Paillet

Reassembling of pictures and tracings of the upper right part of panel $A$ with the calcite slab discovered by N. Aujoulat and J.-J. CleyetMerle in 1999 in the former archeological remains, picture and tracing E. and P. Paillet.

et al. 1908), mais nous en avons retrouvé au moins une dans les collections du MAN (fig. 20). Nous avons longtemps ignoré sa provenance pariétale, et nous ne pensons pas qu'il s'agit de la contre-empreinte présentée à la Société d'Anthropologie de Paris en séance du 9 janvier 1908. "On peut voir, sur la plaque qui est soumise à la Société, une portion de figure de cheval et de quelques autres images. La plaque inférieure, qui portait les gravures, a conservé encore des traces abondantes de celles qui s'étaient déposées au-dessus, à ce point qu'un certain nombre d'images d'animaux y sont indéchiffrables. » (Breuil et al. 1908 - p. 7). La « contreempreinte » du MAN (L. : $43 \mathrm{~cm} ;$ l. : $25 \mathrm{~cm}$; ép. maximale : $6 \mathrm{~cm}$ ) montre quelques tracés assez effacés mais pas le 

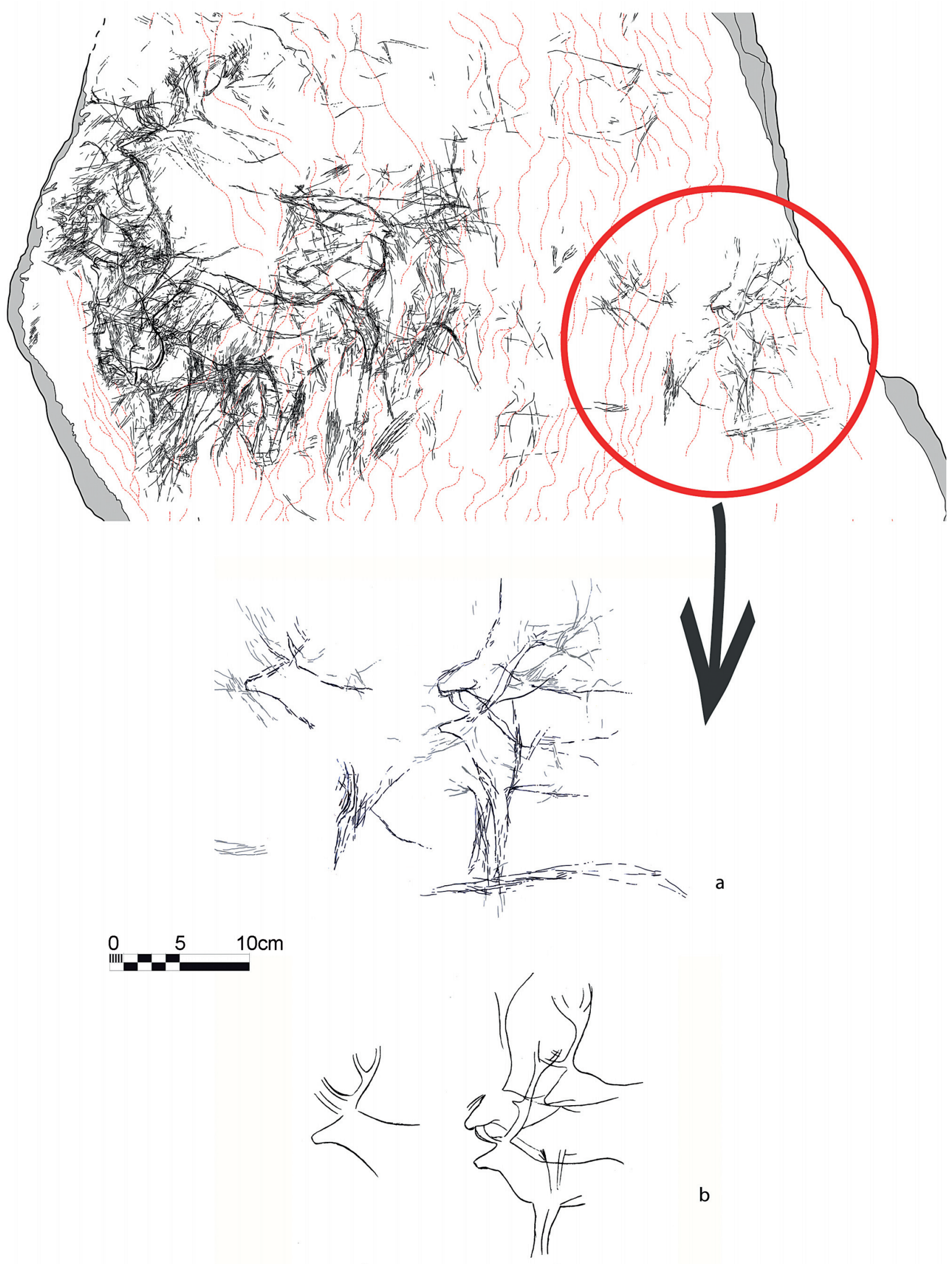

b

- FIGURE 19 -

Relevé de la partie médiane du panneau (ou dalle) C et emplacement du panneau des petits cerfs avec détails, relevés E. et P. Paillet (a) et (b) relevé H. Breuil.
Tracing of the central part of panel $C$ and location of the small deers pattern, tracing E. and P. Paillet (a) and H. Breuil (b). 


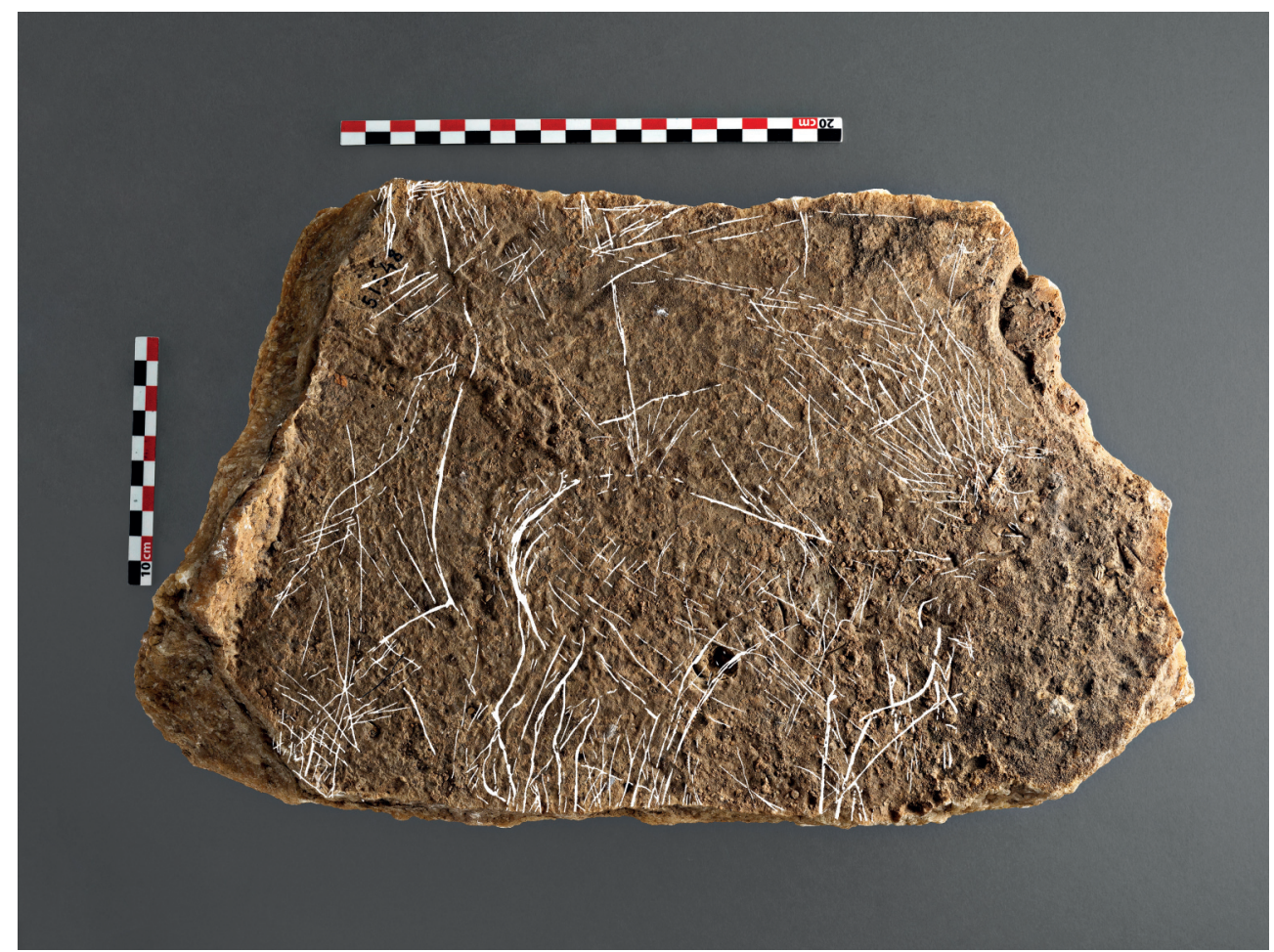

\section{FIGURE 20}

Contre-empreinte de calcite conservée au MAN, photo service photographique du MAN et relevé P. Paillet.

Calcite « contre-empreinte » (natural positive molding) from the MAN, picture MAN and tracing P. Paillet.

cheval décrit plus haut. Par ailleurs, quelle est précisément cette « plaque inférieure » gravée qui est dite difficilement déchiffrables ? Peut-être bien le bloc A avant qu'il ne soit mieux nettoyé ou un autre bloc inédit qui aurait dû alors figurer dans l'inventaire et l'étude des œuvres publiés 4 ans plus tard en 1912 ? La question reste ouverte. Toujours est-il que la contre-empreinte du MAN a, elle, retrouvé récemment sa place dans le dispositif pariétal de la Mairie. L'analyse des caractéristiques de la surface de contact de cette plaque et le relevé des négatifs des gravures, en relief, nous ont permis de l'associer à une partie du bloc actuellement conservé au MNP, ce " morceau de la grotte au musée » découvert dans les déblais par N. Aujoulat et J.-J. Cleyet-Merle en 1999, et évoqué plus haut (fig.21). Nous pensons qu'elle n'a jamais été étudiée par H. Breuil, car dans le cas contraire, il en aurait sans doute donné un relevé et un commentaire.

\section{Une expérimentation de Breuil à la Mairie?}

Nous évoquions plus haut la présence de plusieurs morceaux de dalles de calcite éparses dans les vieux déblais encore abandonnés dans la grotte et notre échec à y lire des gravures et à raccorder ces supports aux restes de la cascade. Pourtant, parmi ces fragments, une dalle (L. : $55 \mathrm{~cm}$; l. : $40 \mathrm{~cm}$, ép. maximale : $20 \mathrm{~cm}$ ) attira notre attention par la présence d'impacts assez frais, par une teinte inhabituelle et par un graffite gravé récent. Cette épaisse dalle avait déjà été remarquée par des responsables du CPIE Périgord-Limousin qui l'avait remisée dans une cave proche. La surface du bloc ne présente aucune gravure attribuable au Paléolithique. Pourtant, elle a été enduite d'un badigeon argileux de couleur ocre puis gravée d'une ligne courbe en forme de rachis dorsolombaire animal. On remarque encore le trait clair qui tranche avec le fond coloré du support. Ce tracé a été ensuite soigneusement détruit par une série de piquetages localisés. Enfin, l'auteur de ce qui ressemble bien à une expérimentation a apposé sa signature à côté de son essai : H. Breuil (fig. 22). La graphie est tout à fait conforme à l'écriture d'Henri Breuil et notamment à sa signature, dans laquelle le B est généralement prolongé par un long jambage. À côté du nom figurent d'autres lettres, et - peut-être - une date que nous n'avons pas pu déchiffrer. On le sait, $\mathrm{H}$. Breuil se singularise très tôt au sein de la communauté scientifique en liant étude et dessin. Bon dessinateur, il met à profit son talent pour mener bien souvent des expérimentations. À Teyjat, il semble que H. Breuil ait réalisé une expérimentation grandeur nature, sur un bloc de stalagmite. Il n'existe cependant aucun témoignage sur cet essai, qui n'est signalé dans aucune publication ni dans ses différents textes autobiographiques. Il s'agit là peut-être de la première expérimentation certaine que l'on puisse lui attribuer (Arnaud Hurel, comm. pers). Ce bloc est actuellement toujours abrité dans la grotte.

\section{Un bison mobilier en deux morceaux au secours du contexte archéologique}

Pour terminer provisoirement ce tour d'horizon, une mention spéciale doit être accordée à l'un des morceaux de calcite découvert en fouille. Nous l'avons évoqué, une dizaine de fragments de calcite (des éléments de planchers et des fragments de stalactites ou de stalagmites) portant des gravures ont été découverts dans les deux niveaux archéologiques lors des fouilles P. Bourrinet. C'est le cas notamment d'une importante dalle de $31,5 \mathrm{~cm}$ de long, $29 \mathrm{~cm}$ de large et $8 \mathrm{~cm}$ d'épaisseur, très finement gravée d'un bison en profil droit. Ses bords émoussés, l'absence de raccords avec les supports pariétaux et le cadrage de l'animal suggèrent le statut d'art mobilier (Tosello 2003 - p. 476) (fig. 23). Elle est anciennement brisée en deux parties. Le plus grand fragment a été mis au jour 


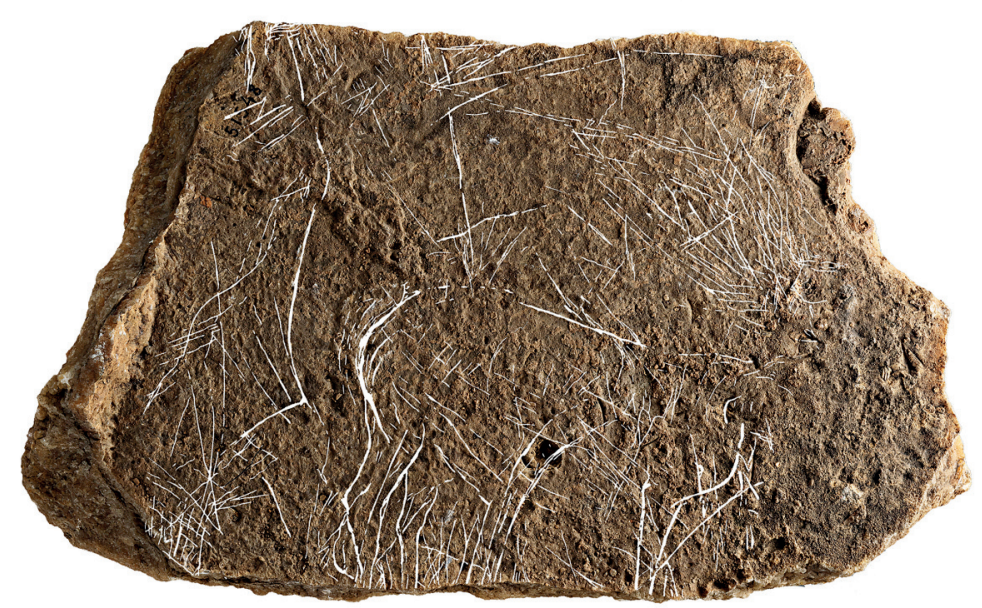

$\mathbf{a}$

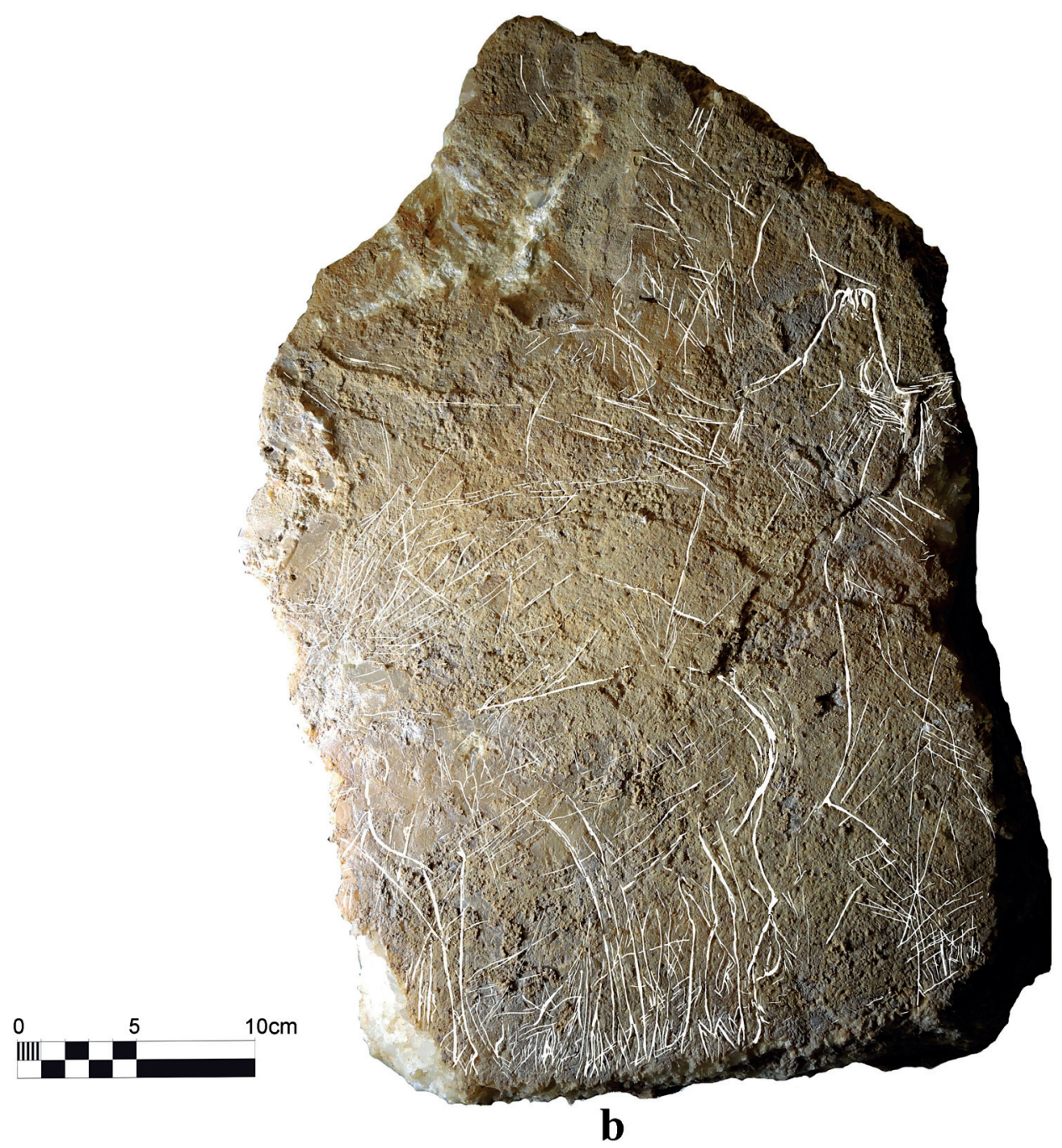

\section{FIGURE 21}

Dalle de calcite gravée découverte par N. Aujoulat et J.-J. Cleyet-Merle en 1999 dans les anciens déblais de la grotte (b) et contreempreinte (a) gravée du MAN avec relevés, photos service photographique du MAN et P. Paillet et relevés P. Paillet.

Engraved calcite slab discovered by N. Aujoulat and I.-J. Cleyet-Merle in 1999 in the former archeological remains (b) with the engraved calcite "contre-empreinte" (a) (natural positive molding) from the MAN with tracings, picture MAN and P. Paillet and tracings P. Paillet. dans le niveau stérile (B) surmontant la couche archéologique inférieure et l'autre morceau, plus petit et portant la queue et la pointe de la fesse du bison, a été recueilli dans le niveau inférieur (A). C'est sur la base de cette découverte et de certaines similitudes stylistiques avec les trois bisons pariétaux que l'art gravé de la cavité a été attribué aux premiers occupants magdaléniens. Mais il n'y a pas lieu ici d'ouvrir le débat sur l'attribution chrono-culturelle précise de l'art pariétal de la Mairie.
Nous avons déjà apporté à ce sujet nos propres arguments (Paillet et al. 2015) et reconsidéré les observations consignées dans la monographie de 1908. Mais c'est peut-être ce statut d'objet autonome accordé à cette dalle au bison qui a fait naître l'interprétation d'un site "mixte ». Cet objet n'est pas le seul fragment de calcite gravé découvert dans les niveaux inférieurs. "Un autre petit morceau de stalagmite porte une patte mal faite et plusieurs autres, quelques traits » (Capitan et al. 1908 - p. 173). Mais la des- 


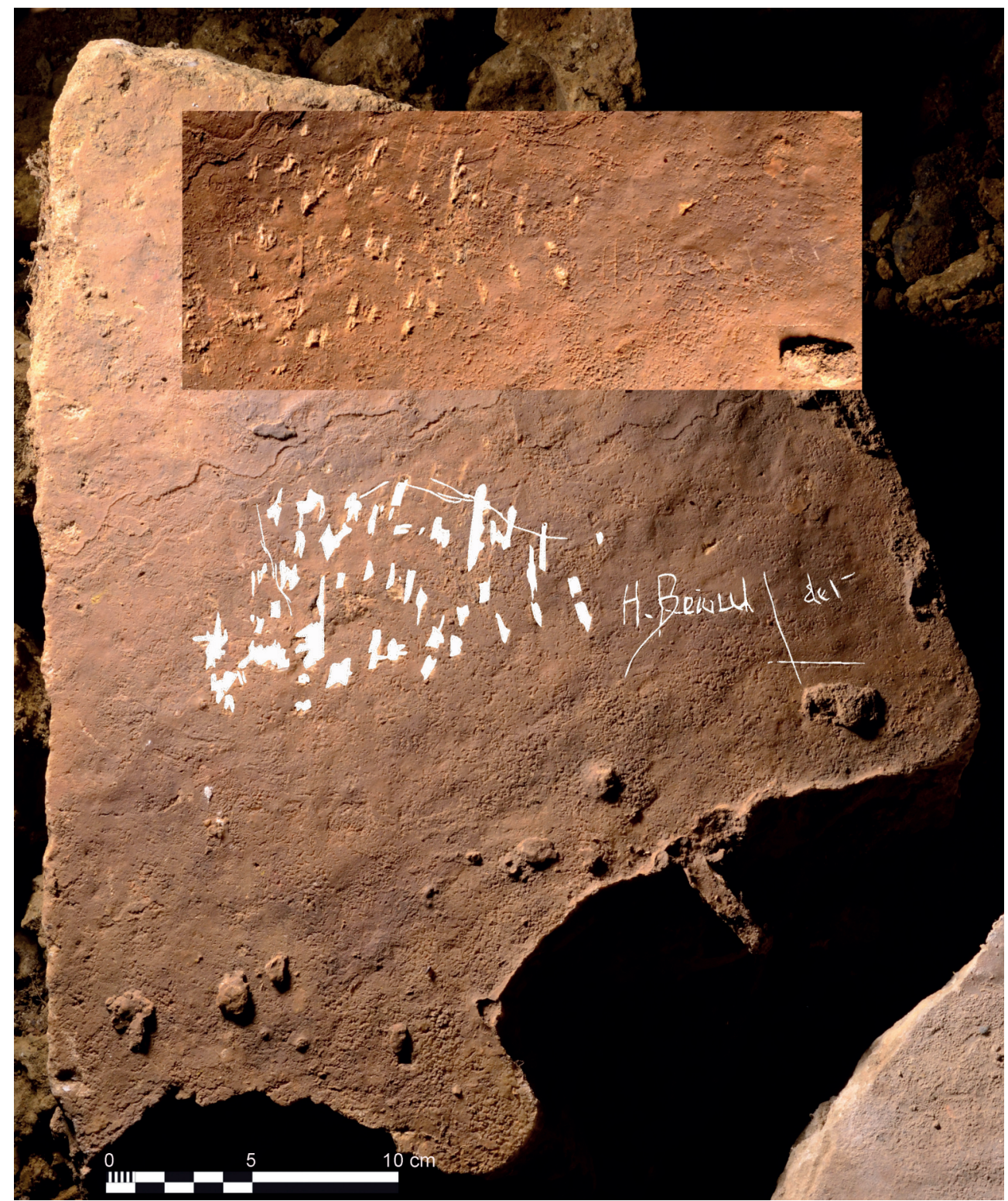

\section{FIGURE 22}

Dalle de calcite recouverte d'un enduit ocré avec traits et impacts récents et signature de $\mathrm{H}$. Breuil, photo J-C. Domenech (MNHN) et relevé P. Paillet.

Calcite slab with ocher deposit and modern engravings and impacts and $\mathrm{H}$. Breuil signature, picture J.-C.5Domenech (MNHN) and tracing P. Paillet.

cription laconique et l'absence de dessin ne permettent pas d'identifier précisément ces objets dans les collections, même si une patte existe bien sur une mince dalle fragmentée dans les séries du MAN (fig. 24). Quatre autres fragments de petite taille également gravés, dont deux sont des éléments de stalactites, ont été découverts dans les niveaux supérieurs, associés à des productions mobilières en os et bois de cervidés (Capitan et al., 1908, p. 216). Ces récoltes semblent bien maigres compte tenu de l'abondance des spéléothèmes dans ce secteur vestibulaire de la grotte. Et si les derniers Magdaléniens avaient sciemment détruit une partie des œuvres pariétales de leurs prédécesseurs pour daller leur sol, il y a fort à parier que P. Bourrinet ou D. Peyrony en auraient collecté beaucoup plus que la petite dizaine d'objets actuellement recensée. Nous pouvons également préciser que le reste de l'art mobilier de la Mairie, est peu abondant et privilégie les supports en matières dures animales (sept pièces dans les couches inférieures A et B et une quinzaine dans les couches supérieures $C$ et D).

\section{CONCLUSION}

La grotte de la Mairie abrite un dispositif pariétal exclusivement gravé sur de très anciens supports stalagmitiques. Il n'existe pas une seule gravure qui soit disposée sur les brèches karstiques du calcaire Bajocien formant l'encaissant de la grotte, supports particulièrement instables et absolument impropres à toutes activités graphiques. Cette caractéristique que la Mairie ne partage, à notre connaissance, avec aucune autre grotte ornée lui vaut une originalité certaine mais aussi son extrême fragilité. L'originalité réside dans cette capacité naturelle que possède la calcite fine et ambrée de la grotte d'enregistrer et de conserver fidèlement la mémoire de toutes les gravures, y compris les plus ténues et de leurs caractéristiques morphologiques et technologiques. Il est encore possible de voir, même à l'œil nu, dans les fonds de traits, les fameux " codes-barres » (Fritz 1999), les éventuels repentirs, les rares corrections et la grande maîtrise technique des graveurs magdaléniens mise au service d'un réalisme réinventé. Il est confié presque uniquement à la ligne de contour 

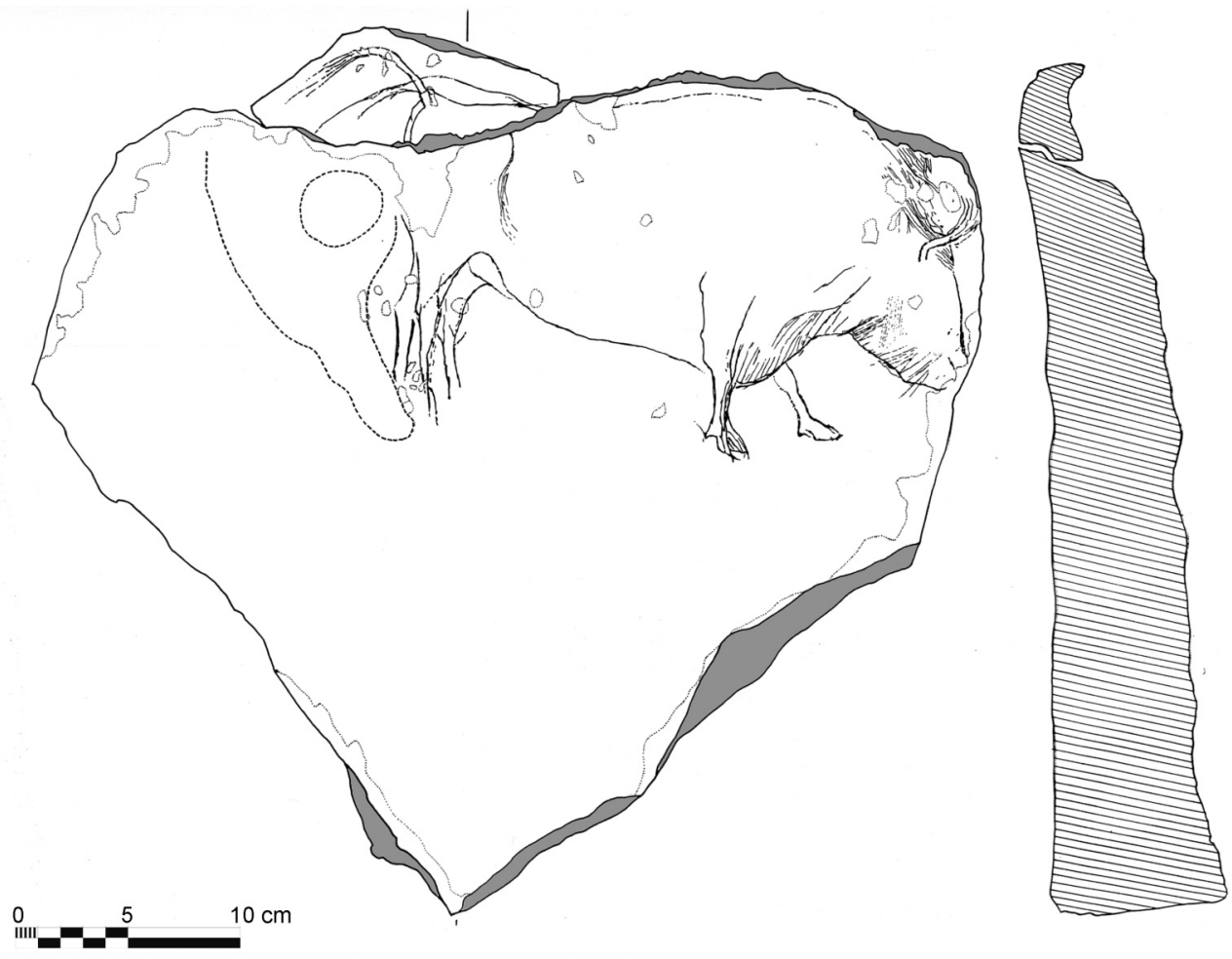

FIGURE 23

Dalle de calcite mobile en 2 morceaux gravée d'un bison, relevé P. Paillet.

Portable calcite slab in two parts engraved with a bison, tracing P. Paillet

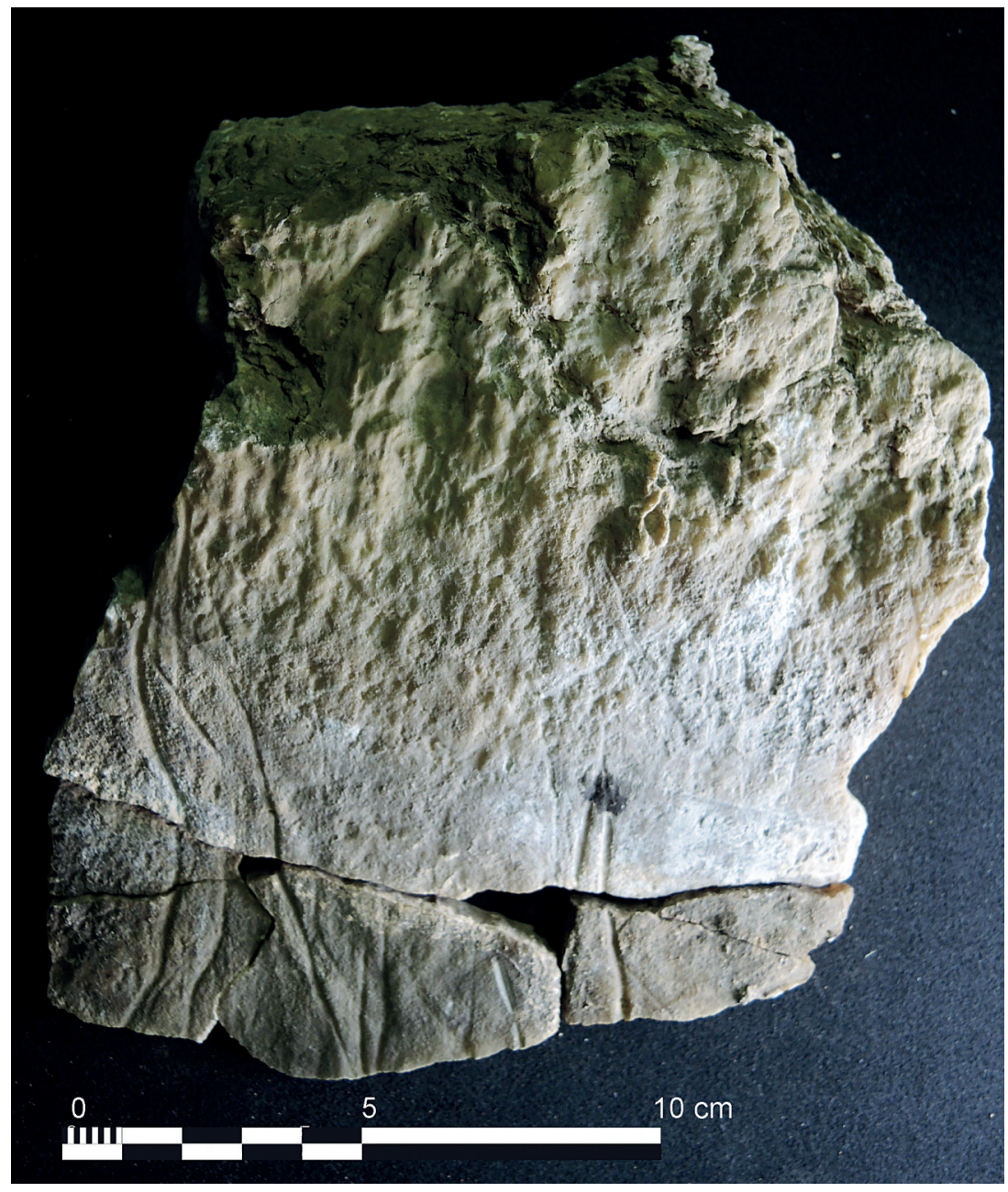

FIGURE 24

Fragments de calcite conservés au MAN avec gravures de pattes animales, photo P. Paillet.

Calcite fragments from the MAN with animal legs engraved, picture P. Paillet. 
associée au propre support de calcite, dont la texture et les microformes ou reliefs sont souvent mises à profit. Les fresques pariétales de la Mairie sont d'une élégance rare et ce qu'elles nous racontent est parfois d'une grande sensibilité. Dès lors nous comprenons qu'André LeroiGourhan les ait situées au sommet de la trajectoire évolutive unilinéaire de l'expression artistique de la Préhistoire qu'il avait élaborée. On sait qu'elle n'a pas résisté à l'affluence des faits nouveaux et au développement des méthodes de datations.

L'art gravé de la Mairie est original mais aussi extrêmement instable. Les planchers et le dôme stalagmitiques imposants qui lui servent de support ont pris naissance dans le système de fissuration de la paroi nord. Au contact de dépôts fluviatiles et de remplissages détritiques constitués d'argiles et d'alluvions à galets, soumis à des évidements, ils se sont édifiés en plusieurs phases successives, dont la plus récente a été datée au LSCE (LSCE ; M. Pierre, E. Pons, D. Genty) par U/Th d'environ 205000 ans. Les étapes de croissance mises en évidence par l'étude morphologique et stratigraphique de la structure sont séparées par de fins liserés millimétriques plus ou moins argileux, des hiatus ou des discontinuités qui correspondent à des interruptions du concrétionnement. La structure feuilletée porte déjà en elle sa propre fragilité. Une mise en charge du réseau à une époque indéterminée laisse sur les flancs du massif stalagmitique des vagues d'érosion de type « coups de gouge ». Avec les vidanges ou les soutirages des remplissages qu'on peut associer à de tels événements, on imagine sans mal les conséquences sur l'intégrité de l'édifice. Et comme si cela ne suffisait pas, l'encaissant calcaire, qui devrait en assurer la protection, apporte épisodiquement, à travers la chute de blocs descellés, sa quote-part à l'endommagement de la stalagmite. La nature a manifestement fait son œuvre. Nous ne savons pas si les Magdaléniens ont été les témoins ou les acteurs de ces destructions, hormis les prélèvements de calcite pour daller le sol, mais dont on ignore la provenance exacte. Nous ne mesurons pas avec précision les conséquences des premières fréquentations historiques, hormis les graffitis. Nous ignorons objectivement si les fouilles de P. Bourrinet et l'aménagement complet de l'entrée de la grotte avec ses nivellements de sols ont eu un réel impact sur la conservation de l'édifice, hormis bien entendu la transformation des régimes aérologiques et du microclimat de la cavité au moins dans sa partie vestibulaire. Il nous appartient maintenant de raisonner sur ce qu'il reste du dispositif pariétal dans la grotte, qui offre encore une certaine unité et une cohérence dans sa construction symbolique, ce que nous avons déjà fait dans le cadre du $P C R$, et des quelques morceaux épars conservés dans les musées, ce que nous venons de proposer ici même. Et pour être aussi souvent dans les musées, la grotte de la Mairie ne serait-elle pas finalement un site «mixte » par l'unique fruit du hasard et de la mobilité accidentelle de ces morceaux de parois?

Il reste aujourd'hui beaucoup à faire dans l'espoir de sauvegarder ce qui reste de ce dispositif fragile. Il faudra, dans les années à venir, mieux comprendre l'histoire géologique et géomorphologique du réseau et de ses environs, approfondir encore l'étude du massif stalagmitique et la chronologie précise de son édification. Il faut enfin et surtout mettre en œuvre sur la durée un programme d'analyses environnementales et d'études microclimatiques du site afin de percevoir ses évolutions à court et moyen termes et tenter d'en prévenir les effets.

\section{RÉFÉRENCES BIBLIOGRAPHIQUES}

ANONYME 1904 - BSHAP (Bulletin de la Société Historique et Archéologique du Périgord). 1904 - Séance du 7 janvier 1904, Tome XXXI, p. 53.

ANONYME 1905 - BSHAP (Bulletin de la Société Historique et Archéologique du Périgord). 1905 - Séance du 27 mai 1905, Tome XXXII, p. 274.

ANONYME 1905 - BSHAP (Bulletin de la Société Historique et Archéologique du Périgord). 1905 - Séance du 7 septembre 1905, Tome XXXII, p. 373-374.

AUJOULAT N. 1984 - Grotte de la Mairie. In : L'art des cavernes. Atlas des grottes ornées françaises, Paris: Ministère de la Culture, Editions du Patrimoine, p. 232-235.

BARRIERE Cl. 1968 - Les gravures de la grotte de la Mairie à Teyjat (Dordogne). Travaux de l'Institut d'Art préhistorique, Toulouse, Tome X, p. 1-12.

BARRIERE Cl. 1972 - Grotte de la Mairie, Teyjat. Une nouvelle petite gravure. Travaux de l'Institut d'Art préhistorique, Toulouse, Tome XIV, p. 203-204.

BOURGES F. 2015 - Le micro-climat de la grotte de la Mairie à Teyjat (Dordogne). In : P. Paillet (dir.), Peuplements et cultures à la fin du Tardiglaciaire dans le nord du Périgord, entre Dronne et Tardoire. Rapport d'opération archéologique, Projet Collectif de Recherche, SRA-DRAC Aquitaine, p. 119-132.

BOURRINET P. 1929 - Mes dernières fouilles à la grotte de la Mairie à Teyjat (Dordogne) (gisement magdalénien). Bulletin de la Société Historique et Archéologique du Périgord, Tome LVI, p. 239-244.

BREUIL H., PEYRONY D. et BOURRINET P. 1908 - Concrétions avec contre-empreinte des gravures de Teyjat. Bulletin de la Société d'Anthropologie de Paris, séance du 9 janvier 1908, p. 6-8.

BRUGIERE H. s.d. - L'ancien et le nouveau Périgord. Périgueux : Archives de la Société historique et archéologique du Périgord (fonds Pommarède).

BRUNET J. et VIDAL P. 1989 - Conservation des grottes ornées. In : L'art pariétal paléolithique, Actes des colloques de la Direction du Patrimoine, Périgueux - Le Thot, novembre 1984, Paris: Ministère de la Culture, de la communication, des Grands travaux et du Bicentenaire, p. 179-191.

CAPITAN L., BREUIL H. et PEYRONY D. 1903 - Une nouvelle grotte à parois gravées à l'époque préhistorique. La grotte de Teyjat (Dordogne). Revue de l'Ecole d'Anthropologie de Paris, XXVIIIe année, p. 364-367 et Comptes rendus des Séances de l'Académie des Inscriptions et Belles Lettre, $47 \mathrm{e}$ année, N5, note présentée le 11 septembre 1903, p. 407-412. 
CAPITAN L., BREUIL H., PEYRONY D. et BOURRINET P. 1905 Recherches effectuées dans la grotte de la Mairie à Teyjat (Dordogne). In : Congrès Préhistorique de France, 1ère Session, Périgueux, p. 86-87.

CAPITAN L., BREUIL H., BOURRINET P. et PEYRONY D. 1908 La grotte de la Mairie à Teyjat (Dordogne). Fouilles d'un gisement magdalénien. Revue de l'Ecole d'Anthropologie, Tome XVIII, mai 1908, p. 153-173 et p. 198-218.

CAPITAN L., BREUIL H., PEYRONY D. et BOURRINET P. 1912 Les gravures sur cascade stalagmitique de la grotte de la Mairie à Teyjat (Dordogne). In : Congrès International d'Anthropologie et d'Archéologie préhistoriques, Compte Rendu de la XIVe session, Genève, p. 498-514.

CHAUVET G. 1905 - Une visite aux grottes de Teyjat. Bulletin et mémoires de la Société archéologique et historique de la Charente, années 1903-1904, 7ème série, Tome IV, p. XLIV-XLIX.

DANDURAND G. 2013 - Quelques indices sur la genèse des grottes de Teyjat (Dordogne). In : P. Paillet (dir.), Peuplements et cultures à la fin du Tardiglaciaire dans le nord du Périgord, entre Dronne et Tardoire. Rapport d'opération archéologique, Projet Collectif de Recherche, SRADRAC Aquitaine, p. 167-171.

DANDURAND G. 2014 -Géologie et géomorphologie de la grotte de la Mairie. In : P. Paillet (dir.), Peuplements et cultures à la fin du Tardiglaciaire dans le nord du Périgord, entre Dronne et Tardoire. Rapport d'opération archéologique, Projet Collectif de Recherche, SRA-DRAC Aquitaine, p. $73-87$

DANDURAND G. 2015 - Topographie et prospections. In : P. Paillet (dir.), Peuplements et cultures à la fin $d u$ Tardiglaciaire dans le nord du Périgord, entre Dronne et Tardoire. Rapport d'opération archéologique, Projet Collectif de Recherche, SRA-DRAC Aquitaine, p. 111-117.

DANDURAND G. 2017 - Sites de Teyjat : la grotte de la Mairie et l'abri Mège (géomorphologie). In : P. Paillet (dir.), Peuplements et cultures à la fin du Tardiglaciaire dans le nord du Périgord, entre Dronne et Tardoire. Rapport d'opération archéologique, Projet Collectif de Recherche, SRADRAC Aquitaine, p. 171-175.

DANDURAND G. 2019 - La grotte de la Mairie (Teyjat), compléments d'analyses. In : P. Paillet (dir.), Rapport final d'opérations archéologiques, SRA-DRAC Aquitaine, p. 123-129.

FAVRAUD A. 1905 - Les grottes de Teyjat. Bulletin et mémoires de la Société archéologique et historique de la Charente, années 1903-1904, 7ème série, Tome IV, p. XCIX-CIII.

FRITZ C. 1999 - La gravure dans l'art mobilier magdalénien, du geste à la représentation. Contribution à l'analyse microscopique. Documents d'Archéologie Française (D.A.F.), n75, Paris: Ed. Maison des sciences de l'homme, 217 p. ill.

GENTY D. et REGNIER E. 2012 - Etude préliminaire des supports et perspectives de recherche. In : P. Paillet (Dir.), Peuplements et cultures à la fin du Tardiglaciaire dans le nord du Périgord, entre Dronne et Tardoire. Rapport d'opération archéologique, Projet Collectif de Recherche, SRADRAC Aquitaine, p. 134-139.
GENTY D. et REGNIER E. 2013 - La grotte de la Mairie Données environnementales. In : P. Paillet (dir.), Peuplements et cultures à la fin du Tardiglaciaire dans le nord du Périgord, entre Dronne et Tardoire. Rapport d'opération archéologique, Projet Collectif de Recherche, SRADRAC Aquitaine, p. 173-179.

GERNIGON K. 2011 - Les blocs gravés paléolithiques de Teyjat (Dordogne). Problématique d'une conservation in situ. Rapport de stage patrimonial de spécialité. Note Conservation/restauration, SRA-DRAC Aquitaine, 11 p., ill.

KONIK S., GENTY D. et REGNIER E. 2014 - Le massif stalagmitique de la grotte de la Mairie. In : P. Paillet (dir.), Peuplements et cultures à la fin du Tardiglaciaire dans le nord du Périgord, entre Dronne et Tardoire. Rapport d'opération archéologique, Projet Collectif de Recherche, SRADRAC Aquitaine, p. 85-93.

LAUGARDIERE P.-H. 1888 - Monographie de la ville et du canton de Nontron (Dordogne). Nontron : Ed. E. Laporte, $412 \mathrm{p}$.

LEROI-GOURHAN A. 1971 - Préhistoire de l'art occidental. Paris : Ed. Mazenod, 499 p., ill.

MANGIER C. 2010-2011 - Art préhistorique et numérisation 3D. Approche méthodologique et comparative des techniques de numérisation 3D. L'exemple du bloc gravé de la grotte de la Mairie (Teyjat, Dordogne). Mémoire de Master 2 Sciences et Technologies, spécialité Préhistoire, Université de Bordeaux 1, 62 p. ill.

PAILLET P. (dir.) 2012 - Peuplements et cultures à la fin du Tardiglaciaire dans le nord du Périgord, entre Dronne et Tardoire. Rapport d'opération archéologique, Projet Collectif de Recherche, SRA-DRAC Aquitaine, 162 p. ill., tabl.

PAILLET P. (dir.) 2013 - Peuplements et cultures à la fin du Tardiglaciaire dans le nord du Périgord, entre Dronne et Tardoire. Rapport d'opération archéologique, Projet Collectif de Recherche, SRA-DRAC Aquitaine, 288 p. ill., tabl.

PAILLET P. (dir.) 2014 - Peuplements et cultures à la fin du Tardiglaciaire dans le nord du Périgord, entre Dronne et Tardoire. Rapport d'opération archéologique, Projet Collectif de Recherche, SRA-DRAC Aquitaine, 203 p. ill., tabl.

PAILLET P. (dir.) 2015 - Peuplements et cultures à la fin du Tardiglaciaire dans le nord du Périgord, entre Dronne et Tardoire. Rapport d'opération archéologique, Projet Collectif de Recherche, SRA-DRAC Aquitaine, 163 p. ill., tabl.

PAILLET P. et MAN-ESTIER E. 2015 - Du pariétal au mobilier dans la grotte de la Mairie, Teyjat (Dordogne). In : O. Rivero et R. Ontañón (Dir.) Symboles dans le paysage : l'art rupestre et son contexte, Actes du XIXe Congrès international d'art rupestre - IFRAO 2015 (31 août - 4 septembre 2015), Caceres (Espagne), Session n 10 « Du sol aux parois: les objets ornés comme contexte de l'art pariétal », ARKEOS 37, Tomar (Portugal), p.693-710. 
PAILLET P. et MAN-ESTIER E. 2016a - Grotte de la Mairie Tamisage des déblais. In : P. Paillet (dir.), Peuplements et cultures à la fin du Tardiglaciaire dans le nord du Périgord, entre Dronne et Tardoire. Rapport d'opération archéologique, Projet Collectif de Recherche, SRA-DRAC Aquitaine, p. 164.

PAILLET P. et MAN-ESTIER E. 2016b - Langage de signes et communication graphique à la fin du Magdalénien. L'art de Rochereil (Grand-Brassac), de l'abri Mège et de la et J.L. SanchidriMairie (Teyjat, Dordogne). In : Cl. Mordant, O. Buchsenschutz, C. Jeunesse et D. Vialou (Dir.) Signes et communication dans les civilisations de la parole (édition électronique et CD), 139ème congrès national des sociétés historiques et scientifiques, Nîmes, 2014, Paris, éditions du CTHS, Edition numérique, p.27-53.

PAILLET P., MAN-ESTIER E., BOCHE E., GAUSSEIN P., LESVIGNES E. et ROBERT E. 2012 - L'art pariétal de la Mairie. In : P. Paillet (Dir.), Peuplements et cultures à la fin $d u$ Tardiglaciaire dans le nord du Périgord, entre Dronne et Tardoire. Rapport d'opération archéologique, Projet Collectif de Recherche, SRA-DRAC Aquitaine, p. 89-114.

PAILLET P., MAN-ESTIER E., DOMENECH J.-C. et LESVIGNES E. 2013 - L'art pariétal de la grotte de la Mairie. In : P. Paillet (Dir.), Peuplements et cultures à la fin du Tardiglaciaire dans le nord du Périgord, entre Dronne et Tardoire. Rapport d'opération archéologique, Projet Collectif de Recherche, SRA-DRAC Aquitaine, p. 181-193.

PAILLET P., MAN-ESTIER E. et DOMENECH J.-C. 2014 - L'art de la grotte de la Mairie. In : P. Paillet (Dir.), Peuplements et cultures à la fin du Tardiglaciaire dans le nord du Périgord, entre Dronne et Tardoire. Rapport d'opération archéologique, Projet Collectif de Recherche, SRA-DRAC Aquitaine, p. 95-119.

PAILLET P., MAN-ESTIER E., BOUDADI-MALIGNE M., DANDURAND G., GENTY D., KONIK S., LAROULANDIE V., MALLYE J.-B. et LANGLAIS M. 2015 - L'art de la grotte de la Mairie (Teyjat, Dordogne) dans son contexte magdalénien. In : D. Garate, A. Medina, A. Ruiz-Redondo et J.-L. Sanchidrián (dir.), Symboles dans le paysage: l'art rupestre et son contexte, Caceres (Espagne), Actes du XIXe Congrès international d'art rupestre - IFRAO 2015 (31 août - 4 septembre 2015), Session $n^{\circ} 6$ « Autour de l'art: le contexte archéologique interne des grottes ornées », ARKEOS 37, Tomar (Portugal), p.429-454.
PERRIER DU CARNE E. 1889 - La grotte de Teyjat. Gravures magdaléniennes. Paris : C. Reinwald Librairie-Editeur., 16 p., ill.

ROTH-GIRALDEZ A.-S. 2014 - Découverte et étude de la grotte de la Mairie à Teyjat (Dordogne) dans le contexte de la reconnaissance de l'art pariétal au début du XXe siècle. Mémoire d'étude de 1ère année - 2e cycle de l'École du Louvre, Paris, 2 volumes, 100 p., ill., tabl.

SAINT-PERIER R. (de) 1948 - Les os gravés de la grotte de la Mairie à Teyjat et leur destinée. Bulletin de la Société Préhistorique Française, Tome 45, p. 230-232.

TOSELLO G. 2003 - Pierres gravées du Périgord magdalénien. Art, symboles, territoires. Paris: CNRS Editions, XXXVIe supplément à Gallia-Préhistoire, 577 p., ill.

WAREMBOURG J.-M. 2017 - Pierre Bourrinet et l'histoire des découvertes préhistoriques à Teyjat. Bruges: Editions des Hautes Terres, 198 p., ill.

\section{Archives consultées}

- Médiathèque de l'Architecture et du Patrimoine, série 1996/025-Casier archéologique

- Correspondance de L. Capitan à H. Breuil

- Lettre de D. Peyrony à H. Breuil, 5 avril 1904

- Lettre de A. Roussot à F. Bordes, 27 novembre 1963

- Musée national de Préhistoire, fonds D. Peyrony 